\title{
Molecular Targets Related to Inflammation and Insulin Resistance and Potential Interventions
}

\author{
Sandro M. Hirabara, ${ }^{1,2}$ Renata Gorjão, ${ }^{1}$ Marco A. Vinolo, ${ }^{3}$ Alice C. Rodrigues, ${ }^{2}$ \\ Renato T. Nachbar, ${ }^{2}$ and Rui Curi ${ }^{2}$
}

${ }^{1}$ Institute of Physical Activity Sciences and Sports, Cruzeiro do Sul University, 01506-000 São Paulo, SP, Brazil

${ }^{2}$ Institute of Biomedical Sciences, University of São Paulo, 05508-900 São Paulo, SP, Brazil

${ }^{3}$ Institute of Biology, University State of Campinas, 13083-970 Campinas, SP, Brazil

Correspondence should be addressed to Sandro M. Hirabara, sandromh@yahoo.com.br

Received 6 July 2012; Revised 13 September 2012; Accepted 13 September 2012

Academic Editor: Hartmut Jaeschke

Copyright (C) 2012 Sandro M. Hirabara et al. This is an open access article distributed under the Creative Commons Attribution License, which permits unrestricted use, distribution, and reproduction in any medium, provided the original work is properly cited.

Inflammation and insulin resistance are common in several chronic diseases, such as obesity, type 2 diabetes mellitus, metabolic syndrome, cancer, and cardiovascular diseases. Various studies show a relationship between these two factors, although the mechanisms involved are not completely understood yet. Here, we discuss the molecular basis of insulin resistance and inflammation and the molecular aspects on inflammatory pathways interfering in insulin action. Moreover, we explore interventions based on molecular targets for preventing or treating correlated disorders, advances for a better characterization, and understanding of the mechanisms and mediators involved in the different inflammatory and insulin resistance conditions. Finally, we address biotechnological studies for the development of new potential therapies and interventions.

\section{Crosstalk between Inflammatory Pathways and Insulin Signaling}

1.1. Mechanism of Insulin Action. Insulin receptor is a tetramer protein composed by two extracellular $\alpha$ subunits and two transmembrane $\beta$ subunits. The $\alpha$ subunits have a binding site to insulin while the $\beta$ subunits contain an intrinsic tyrosine kinase activity towards intracellular side. Insulin binding to the $\alpha$ subunit leads to a conformational change and activation of the $\beta$ subunit, resulting in tyrosyl autophosphorylation of the insulin receptor. After being activated and phosphorylated, several intracellular docking proteins bind to the insulin receptor and are also tyrosyl phosphorylated, including insulin receptor substrates 1 and 2 (IRS-1 and IRS-2) [1, 2], Src homology collagen (SHC), and associated protein substrate (APS) [3]. IRS proteins are the major and better characterized proteins involved in insulin signaling. These proteins activate several signaling pathways involved in the regulation of important cellular events such as glucose uptake and metabolism, protein synthesis, gene expression, cell survival, growth, development, and differentiation [4-6]. IRS proteins are phosphorylated on various tyrosine residues of the C-terminal region, generating specific sites for binding of proteins containing Src homoly-2 (SH2) domains, including phosphatidylinositol3 kinase (PI-3K), Nck, and Grb-2. PI-3K is composed by a catalytic subunit (p110) and a regulatory subunit (p85). This kinase is an important signaling molecule, mediating metabolic effects of the insulin. Binding of p85 subunit to phosphorylated tyrosine residues of IRS proteins leads to activation of the catalytic activity of p110 subunit and subsequent increase in the generation of phosphatidylinositol 3,4-bisphosphate (PIP2) and phosphatidylinositol 3,4,5trisphosphate (PIP3) content. Downstream proteins from PI3 K pathway comprehend several serine/threonine kinases, for example, phosphoinositide-dependent protein kinase-1 (PDK-1), protein kinase B (PKB, also known as Akt), protein kinase C (PKC), p70 S6 kinase (p70S6 K), and glycogen synthase kinase-3 (GSK-3). These kinases are involved in the most important biological effects induced by insulin, such as translocation of glucose transporter-4 (GLUT-4) from intracellular vesicles to plasma membrane, glycogen and protein synthesis, antiapoptotic effects, and gene expression (Figure 1) [7-11]. 


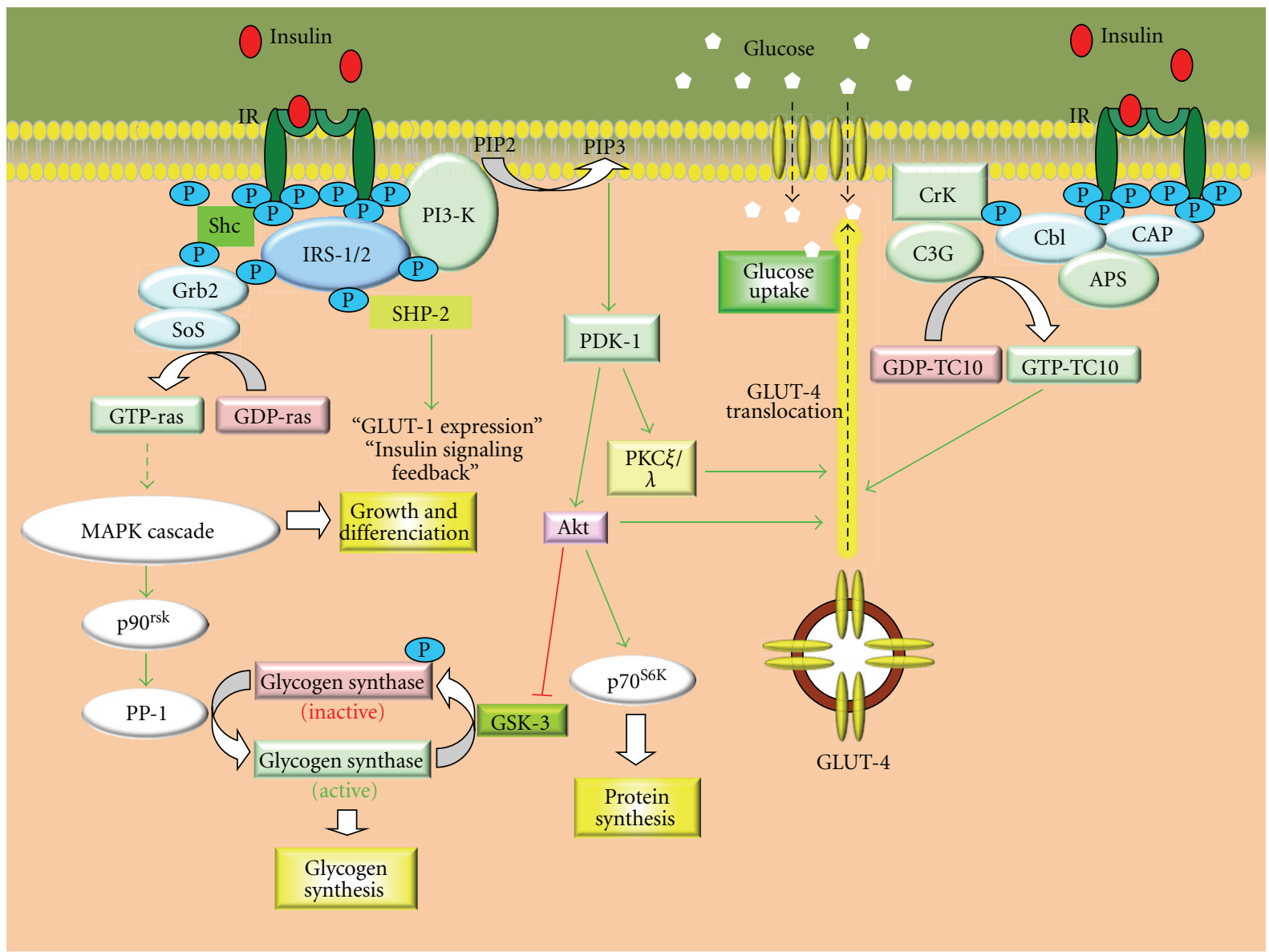

FIGURE 1: Summary of the main insulin signaling pathways. GLUT-1 and -4: glucose transporter-1 and -4; Grb-2: growth receptor binding-2; GSK-3: glycogen synthase kinase-3; IR: insulin receptor; IRS-1 and -2: insulin receptor substrate-1 and -2; MAPK: mitogen-activated protein kinase; PDK-1: phosphoinositide-dependent kinase-1; PIP2: phosphatidyl-inositol diphosphate; PI3: phosphatidyl-inositol triphosphate; P: phosphate; PKC: protein kinase C; PP-1: phosphoprotein phosphatase-1; p70S6 K: protein 70 S6 kinase; p90rsk: protein 90 ribosomal S6 kinase; Shc: Src homology collagen; SHP-2: phosphatase with Src homology 2 domain; SoS: Son of Sevenless.

Other signaling pathways involved in the glucose uptake induced by insulin start with the recruitment of APS to the activated insulin receptor and subsequent association and tyrosine phosphorylation of $\mathrm{Cbl}$, which interacts with $\mathrm{Cbl}$ associated protein (CAP) through an SH3 domain and with flotillin, a constituent of lipid raft, through a sorbin domain. The complex CrkII/C3G then binds to the phosphorylated tyrosine residues of $\mathrm{Cbl}$, activating the $\mathrm{C} 3 \mathrm{G}$ activity that exchanges GDP for GTP of TC10, a small G-protein that belongs to the Rho family. After being activated, TC10 participates in the GLUT-4 translocation (Figure 1) [12-16].

Mitogen-activated protein kinase (MAPK) cascade starts with the association of Shc to insulin receptor, binding of Grb-2 to Shc or to IRS-1, and formation of the Grb-2/SoS (Son of Sevenless) in the plasma membrane [17-19]. This complex leads to the activation of c-Ras and raf, starting the MAPK cascade [20]. MAPK pathway is involved in the differentiation, cell growth, and development induced by insulin [21], as well as some metabolic effects, as glycogen synthesis and GLUT-4 translocation to plasma membrane (Figure 1) [22-24]. However, this cascade is not enough or even required to this later effect [25].
Disturbances in several proteins involved in the insulin signaling pathways have been found in different conditions of insulin resistance, including obesity, type 2 diabetes mellitus, metabolic syndrome, cardiovascular diseases, inflammatory disorders, and cancer [26-28]. Here, we will discuss possible mechanisms involved in the development of insulin resistance related to inflammatory processes.

1.2. Molecular Basis of Insulin Resistance. Insulin resistance occurs when the insulin-sensitive tissues, mainly skeletal muscle, adipose tissue, and liver, lose the ability to respond properly to the hormone $[29,30]$. It is associated with several chronic diseases, especially those linked to obesity, such as type 2 diabetes mellitus, metabolic syndrome, dyslipidemias, cardiovascular diseases, cancer, and neurodegenerative diseases [31-33]. However, the precise mechanisms involved in insulin resistance are not fully understood yet [3437]. Several factors have been proposed to participate in the development of insulin resistance, including increased plasma-free fatty acid level, subclinical chronic inflammation, oxidative and nitrative stress, altered gene expression, and mitochondrial dysfunction $[29,37]$. 
Since free fatty acids are elevated in obesity and related diseases, these metabolites have been proposed to be responsible for the impairment in the insulin action, but the mechanisms are not completely known yet $[38,39]$. High availability of fatty acids, specially long-chain saturated fatty acids, results in the establishment of insulin resistance in liver, skeletal muscle, and adipose tissue $[40,41]$. Various hypothesis have been proposed to explain the insulin resistance induced by saturated fatty acids, including Randle cycle, oxidative stress, modulation of gene transcription, inflammation, accumulation of intracellular lipid derivatives (diacylglycerol and ceramides), and mitochondrial dysfunction [42-47] (for review, see Martins et al. [37]).

A chronic state of inflammation in the insulin responsive tissues is a major contributor to insulin resistance in obesity and related diseases. Thus, a crosstalking between inflammation and insulin resistance has been suggested by several authors. However, the precise mechanism as well as the mediators involved in this interaction is not completely defined yet. In this paper, we discuss how inflammatory signaling pathways impair insulin signaling (see below).

Intracellular redox balance is a finely regulated process that involves several generating pathways and degrading systems. Physiologically, ROS participate in important biological responses, but accumulation of these molecules leads to oxidative stress condition [48]. ROS are highly oxidant molecules that can oxidize various intracellular components, including membrane phospholipids, proteins, and DNA $[49,50]$. Usually, these reactions cause cellular damage, reducing the function of oxidized biomolecules. In insulin resistance, increased ROS production and/or decreased ROS degradation is observed, leading to an oxidative stress condition [51] and activation of signaling pathways related to stress. There is evidence that oxidative stress is also involved in muscle disorders, contributing to the insulin resistance process. Transgenic mice expressing human ubiquitin protein E3 ligase, a protein that binds and promotes degradation of superoxide dismutase-1, resulting in reduced superoxide degradation and consequently oxidative stress, present muscle dysfunction (atrophy and sclerosis) [52].

Activation of signaling pathways to stress has been suggested to participate in the development of insulin resistance by impairing the signaling by this hormone. Several serine/ threonine kinases activated by oxidative stress pathways, including JNK, PKC, GSK-3, NF-kB, and p38 MAPK, have been suggested to impair insulin signaling pathways $[53,54]$, as described below.

Expression of several genes is also altered in insulin resistance conditions. For example, expression of genes involved in lipid and glucose metabolism, insulin signaling, inflammation, redox balance, and mitochondrial function is modified, suggesting that these processes participate in the pathophysiology of insulin resistance [55-57]. Disturbed mitochondrial function has been suggested to have a central role in these alterations, since this organelle participates in all these processes (for review, see Martins et al. [37]).

1.3. Molecular Basis of Inflammation. Inflammation is a coordinated process evoked by the tissues in response to noxious stimuli or conditions including the presence of infection, tissue injury, or malfunction. The inflammatory response is activated by molecules released by microorganisms including microbial associated molecular patterns (MAMPs) such as lipopolysaccharide, flagellin, and peptidoglycans or produced/released by host cells including intracellular components, the so-called damage-associated molecular patterns (DAMPs), of which, HMGB1, DNA, and nucleotides are part. These inducers of inflammation bind to their respective receptors and activate biological responses by the resident cells, mainly, macrophages and mast cells. These cells act directly or indirectly on the vasculature and on leukocytes to induce, among other effects, the migration of leukocytes and extravasations of plasma proteins to the tissues [58].

Several receptors have been demonstrated to act as cell sensors of damage or infection. Examples of proteins with this function include the receptors of the toll-like (TLRs) family, the C-type lectin receptors, the purinergic and advanced glycation endproducts receptors (RAGE), and the intracellular nucleotide oligomerization domain (NOD), and retinoic acid-inducible gene (RIG)-I-like receptors (RLRs). After recognizing their ligands, several downstream pathways including c-Jun $\mathrm{NH}(2)$-terminal kinase (JNK) and $\mathrm{I} \kappa \mathrm{B}$ kinase complex (IKK) are activated, resulting in changes on transcription factors activity and expression of proteins such as cytokines, enzymes, chemokines, adhesion molecules, and amplification of the inflammatory response.

The activation of the inflammatory pathways described above is a hallmark of obesity, and it has been associated with the development of insulin resistance, atherosclerosis, and other tissue dysfunctions that are secondary to fat accumulation. An increased production of inflammatory mediators and activation of inflammatory pathways in several tissues including adipose tissue (AT), liver, pancreas, skeletal muscle, and hypothalamus are present in obese individuals [59] and define a subclinical inflammatory process also known as "meta-inflammation" (metabolically induced inflammation) [60].

In opposition to other inflammatory conditions, little information is available regarding the inducers and sensors involved in obesity-associated inflammation. In this respect, some hypotheses to explain the initial activation/recruitment of leukocyte to the tissues (mainly, AT) have been proposed. The release of DAMPs by necrotic adipose cells, the increase in the flux of nonesterified fatty acids (increased rates of lipolysis), the reduction in the oxygen tension (hypoxia) leading to activation of hypoxia-induced factor (HIF)-1, which controls the expression of proinflammatory proteins, and the production of chemokines by adipose cells have been suggested to play a role in the initiation of inflammatory process [61]. Despite several advances in the field, the initial events involved in the beginning of inflammation in the AT and the complex interactions between them are not clearly understood, and new components are continuously described and added to the puzzle such as leukotrienes and the apoptosis inhibitor of macrophage (AIM) [62, 63]. This latter protein has been shown to stimulate lipolysis in adipocytes. The release of fatty acids, through interaction 


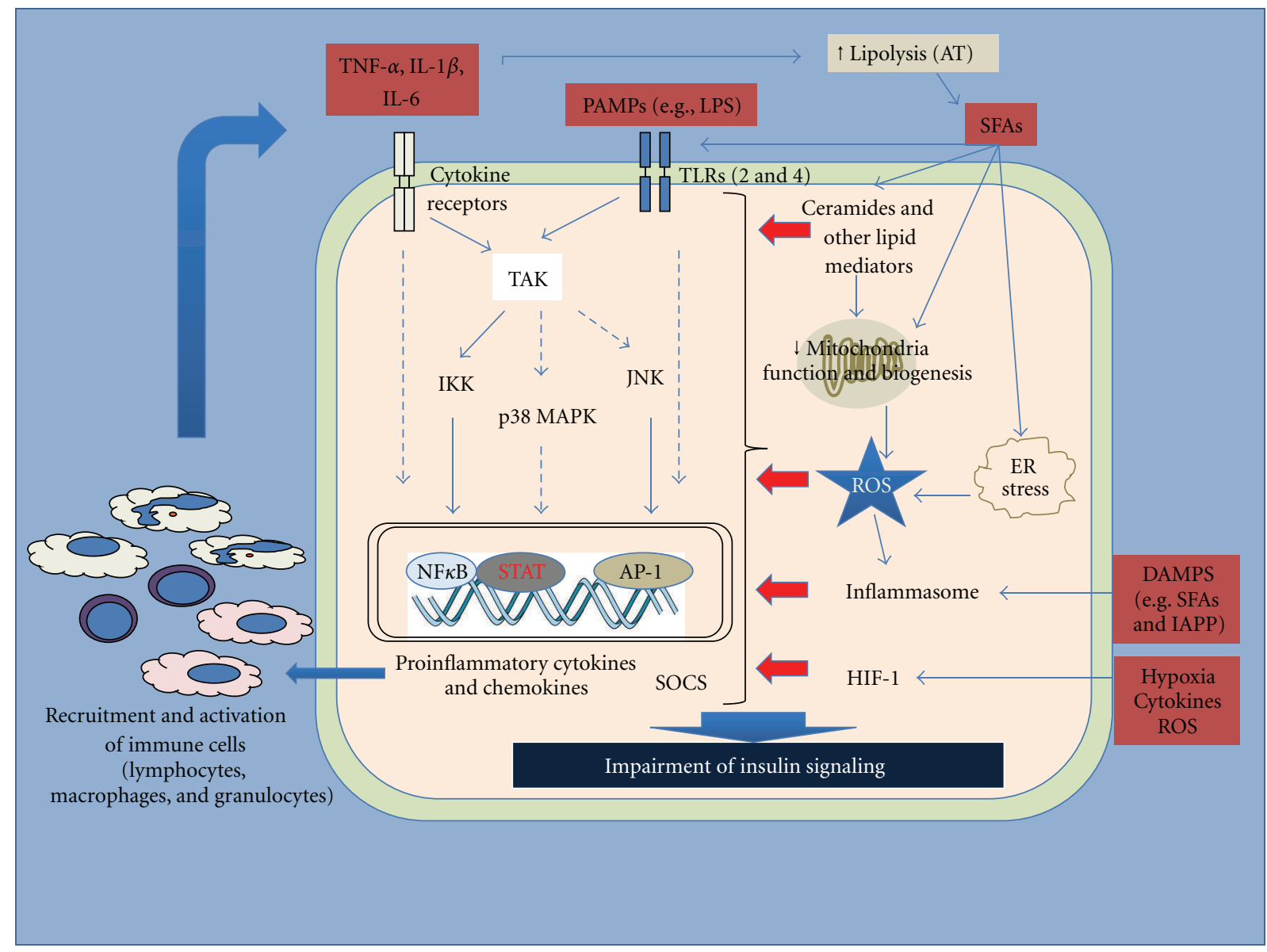

FIGURE 2: Inflammatory pathways activated during obesity and their cross talk with insulin signaling. Different signals act directly through membrane (e.g., toll-like receptors [TLRs] and cytokine receptors) and intracellular proteins (inflammasomes) or indirectly by their effect on cell organelles such as mitochondria and endosomal reticulum and generation of metabolites (e.g., ceramides and other lipid mediators) to activate inflammatory pathways. Transcription factor such as nuclear factor $\kappa \mathrm{B}(\mathrm{NF} \kappa \mathrm{B})$, activator protein-1 (AP-1), and signal transducers and activators of transcription (STAT) are activated downstream to these pathways and lead to the expression of proteins that inhibit insulin signaling and induce a pro-inflammatory state by recruiting and activating immune cells. AT, adipose tissue; DAMPS, damage associated molecular patterns; ER, endoplasmic reticulum; HIF-1, hypoxia factor-1; IAPP, islet amyloid polypeptide; PAMPS, pathogen associated molecular patterns; ROS, reactive oxygen species; SFAs, saturated fatty acids; SOCS, suppressor of cytokine signaling; TAK, transforming growth factor $\beta$-activated kinase.

with TLR4, induces the expression of chemokines that lead to macrophage recruitment [63].

The obesity-induced inflammation is associated with activation of resident cells such as Kupffer cells in the liver [64] and leukocyte infiltration and shift in the polarized state of tissue/recruited leukocytes. These changes are better characterized in the adipose tissue, in which an increased infiltration by proinflammatory M1-type macrophages (classical macrophages), Th1, Th17 and CD8 ${ }^{+} \mathrm{T}$ cells and a reduction in the content of less inflammatory cells such as M2macrophage, T reg, and Th2 cells were demonstrated [6568]. The overproduction of inflammatory mediators by the infiltrating cells together with changes in adipokines production and NEFA release by AT contribute to the tissue dysfunctions observed in obesity, as discussed below.
1.4. Relationship between Inflammation and Insulin Resistance. Several chronic diseases are characterized by increased inflammatory process and insulin resistance, such as obesity, type 2 diabetes mellitus, metabolic syndrome, cardiovascular diseases, and cancer [50]. The relationship between these two factors has been proposed by several authors. For example, various studies suggest the involvement of some inflammatory factors in the development of insulin resistance, including cytokines (TNF- $\alpha$, IL-1, IL-6), ROS, and RNS (Figure 2). These factors lead to the activation of signaling pathways that ultimately impair insulin signaling (see below). In addition, other factors involved in inflammatory processes also can impair insulin sensitivity, particularly lipopolysaccharides (LPSs) and environmental stress (hypoxia, nutrients, and $\mathrm{pH}$ ) (Figure 2). 
TLRs comprehend a family of receptors involved in the recognition of microbes. It has been demonstrated that fatty acids, specially saturated fatty acids, are able to activate TLR4 in skeletal muscle cells, resulting in increased activity of IKK and JNK. The first kinase degrades the inhibitor of $\kappa \mathrm{B}$ $(\mathrm{I} \kappa \mathrm{B} \alpha)$, resulting in the nuclear factor- $\kappa \mathrm{B}(\mathrm{NF} \kappa \mathrm{B})$ release and migration to the cell nucleus, where it induces the transcription of proinflammatory genes. The second kinase activates members of the signal transducers and activators of transcription (STAT) family, which are involved in several biological effects, such as expression of genes related to inflammation, apoptosis, differentiation, growth, morphogenesis, migration, and proliferation [69]. Both JNK and IKK $\beta$ have been proposed to be the mediators of insulin resistance induced by saturated fatty acids (Figure 2). It has been shown that these kinases phosphorylate serine residues on IRS proteins, blocking IRS phosphorylation on tyrosine residues by the activated insulin receptor [70] and consequently inhibiting insulin effects [71]. Moreover, phosphorylation on serine/threonine residues also increases IRS protein degradation, contributing to the establishment of insulin resistance [71-73].

These effects are confirmed by several studies involving gene manipulation. Nonfunctional TLR-4 expression protects mice from insulin resistance and inflammation induced by high-fat diet [74], and TLR-4 gene silencing by small interference of RNA reduces inflammation in acute lung injury induced by lipopolysaccharide [75]. Obese and type 2 diabetic animals are prevented from insulin resistance and inflammation by specific inhibitors or gene mutation (knockout or nonfunctional gene) of IKK or JNK [76-78].

Possible mediators of inflammation and insulin resistance are the fatty acids. These metabolites have been linked to the establishment of inflammatory process, by modulating several signaling pathways related to inflammation. For example, fatty acids can directly activate toll-like receptors (TLRs), G-protein coupled receptors (GPCRs), and tumor necrosis factor- $\alpha$ (TNF- $\alpha$ ) receptor as well as modulate inflammatory signaling pathways involved in the increase in cytokine secretion (TNF- $\alpha$, IL- $1 \beta$, and IL-6) $[60,79$, 80 ], oxidative and nitrative stress, mitochondrial dysfunction, endoplasmic reticulum (ER) stress, and proinflammatory gene expression. Alterations in the expression of genes and proteins involved in the inflammatory process are clearly associated with insulin resistance and several metabolic abnormalities, including mitochondrial dysfunction, decreased fat oxidation, increased ectopic lipid storage, and impaired insulin signaling pathways (Figure 2) [81].

Proinflammatory cytokines were also involved in the reduction of mitochondrial function $[79,82]$. Palmitatestimulated IL-1 $\beta$ production in macrophages occurs via NLRP3-ASC inflammasome and participates in the mitochondrial dysfunction induced by this fatty acid. This dysfunction is also observed when the cells are exposed to other cytokines, such as TNF- $\alpha$ or IL-6 $[83,84]$.

Therapies aimed at neutralizing proinflammatory cytokines such as TNF- $\alpha$ and IL- $1 \beta$, such as the monoclonal antibody infliximab and canakinumab, respectively, have been under investigation in the treatment of type 2 diabetic patients. Considering anti-TNF antibodies, the results are disappointing as many clinical trials in type 2 diabetic patients have failed to demonstrate an effect of TNF neutralization on insulin sensitivity [85-89]. On the other hand, in patients with high grade inflammatory diseases such as rheumatoid arthritis and ankylosing spondylitis, anti-TNF therapy has been successfully associated with reduction in insulin resistance and metabolic syndrome components [9095]. The molecular mechanisms of TNF- $\alpha$ blockade on insulin signaling were related to reduction in IRS-1 serine phosphorylation and increase in AKT phosphorylation in peripheral mononuclear cells from rheumatoid arthritis patients [95].

Potential effects of IL- $1 \beta$ blockade on insulin sensitivity are current under investigation in humans. The long-term effects of anti-IL-1 $\beta$ therapy are now examined in the large phase III clinical trial CANTOS (Canakinumab Antiinflammatory Thrombosis Outcomes Study) [96]. The study included and treated 17,200 patients with various doses of anti-IL- $1 \beta$ antibody every 3 months and followed up over 4 years. The primary endpoint of the CANTOS study will be cardiovascular events, and secondary endpoints include new onset type 2 diabetes and diabetes-specific markers. Such large and long-term trials could provide a novel cytokinebased therapy for the secondary prevention of new-onset diabetes as well as confirm the autoinflammatory nature of metabolic disorders.

Another potential molecular target for treatment of inflammatory diseases is JNK. This kinase regulates both the development of insulin resistance and inflammation. However, identification of pharmacologically potent and selective small molecule JNK inhibitors has been limited. Compound A, a reversible ATP-competitive aminopyridine inhibitor of JNK, was developed by Pfizer. Testing this compound in obese mice decreased their body weight as well as blood glucose and triglyceride concentrations and increased insulin sensitivity to levels comparable to those in lean control mice [97]. A substrate competitive inhibitor of JNK, BI-78D3, has also been shown to restore insulin sensitivity in a murine model of type 2 diabetes after a single dose [98]. A more recent drug discovery is the compound 19, a potent and selective dual substrate and ATP-competitive JNK bidentate inhibitor [99]. Glucose intolerant NONcNZO10/LtJ mice were injected intraperitoneally daily for four days with $25 \mathrm{mg} / \mathrm{kg} \mathrm{19}$, and this compound was remarkably effective in restoring normoglycemia without inducing hypoglycemia compared to the vehicle control. These studies demonstrate that inhibition of JNK is an effective strategy to ameliorate insulin resistance. However clinical trials are needed to test these compounds in humans and show their efficacy and long-term toxicity.

\section{Identification of New Molecular Targets for Reducing Inflammation in Insulin Resistance Models}

2.1. GPCRs. G-protein coupled receptors (GPCRs) constitute a family of membrane proteins characterized by 


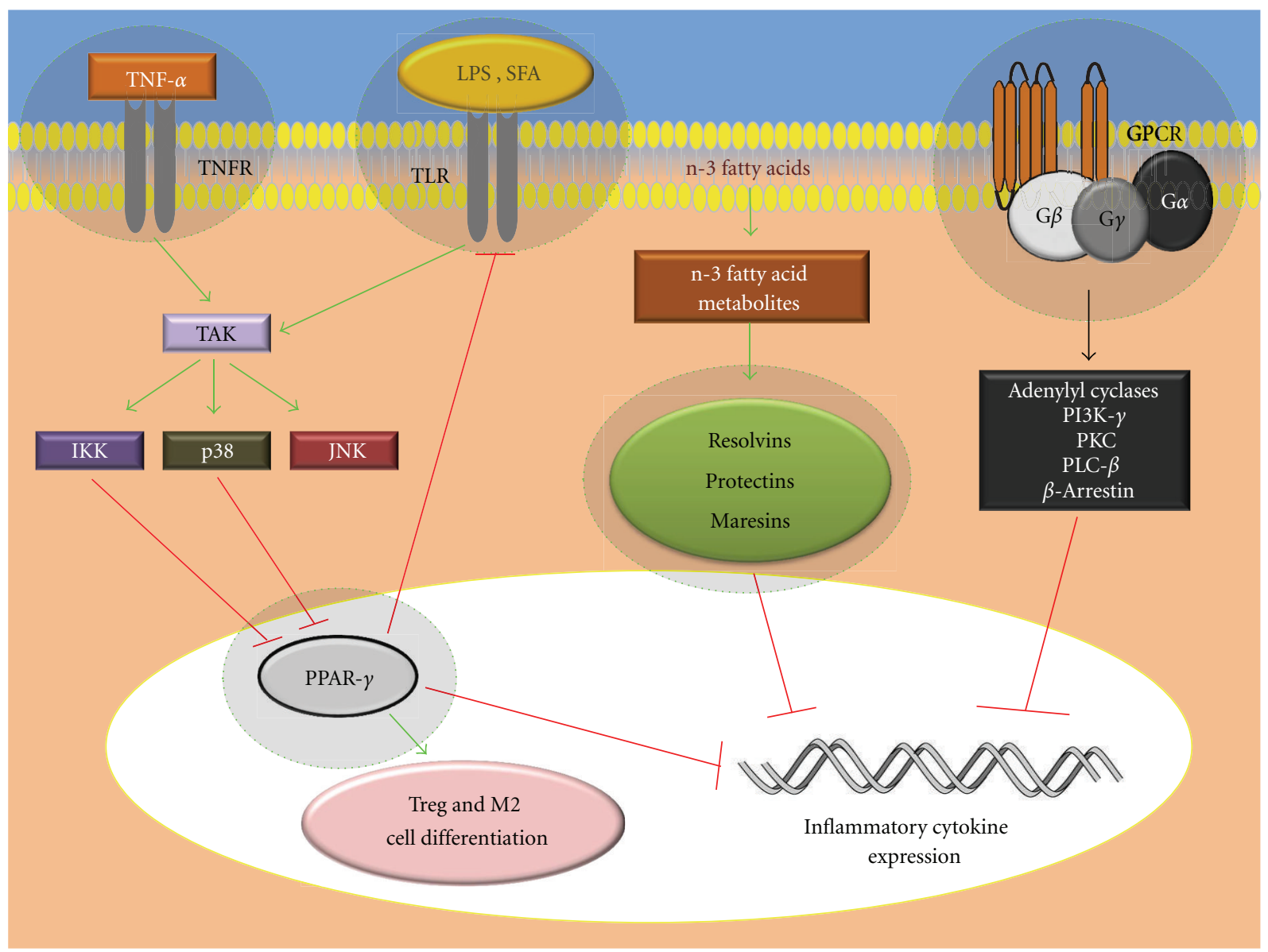

FIGURE 3: Potential molecular targets for reducing inflammation in insulin resistance conditions. Circulated proteins and lipid mediators are included as potential targets. Resolvins, protectins, and maresins are lipid mediators generated from n-3 fatty acid metabolism that have potent anti-inflammatory and immunoregulatory actions, promoting decreased inflammatory cytokine expression. Toll-like receptors (TLRs) are transmembrane receptors that are activated by saturated fatty acids (SFAs) and lipopolysaccharides (LPSs) inducing inflammatory responses. TLRs activate intracellular pathways that inhibit the peroxisome proliferator-activated receptor- $\gamma$ (PPAR- $\gamma$ activity). This transcriptional factor is involved with decreased inflammatory cytokine expression and increased Treg cell differentiation. Other cytokines, including tumor necrosis factor- $\alpha$ (TNF- $\alpha$ ), also promote PPAR- $\gamma$ inhibition. G-protein coupled receptor (GPCR) activation may attenuate the production of TNF- $\alpha$, interleucin-6 (IL-6) and macrophage chemoattractant protein-1. GPR120 is a GPCR activated by n-3 fatty acids in insulin resistance models. COX: cyclooxygenase; IKK: I $\kappa$ B kinase; JNK: c-Jun NH(2)-terminal kinase; PI3 K- $\gamma$ : phosphatidylinositol 3kinase- $\gamma$; PKC: protein kinase C; PLC- $\beta$ : phospholipase C- $\beta$.

a common motif, the seven transmembrane domains. Ligand binding to these receptors leads to conformational changes in the receptor and activation of intracellular guanine nucleotide-binding proteins (G-proteins). Several enzymes including adenylyl and guanylyl cyclases, phospholipases A2 and $\mathrm{C}$, phosphodiesterases and phosphatidylinositol 3-kinases (PI3Ks) and other intracellular transduction cascades are triggered downstream to these receptors. These pathways affect both the insulin signaling and the inflammatory proteins expression (Figure 3).

In the recent years, new GPCRs were described and deorphanized. Several of these receptors have been shown to regulate insulin secretion and tissue sensibility to this hormone, becoming potential targets for intervention in conditions of insulin resistance/deficiency. In this paper, we will briefly discuss a class of GPCRs that share in common the fact of being activated by fatty acids (FAs-GPCRs). Other
GPCRs implicated in the glucose metabolism and regulation of inflammation such as GLP-1, glucose-dependent insulinotropic polypeptide (GIP), the bile acid (TGR5), cholecystokinin, the cannabinoid receptors (CBs), and muscarinic receptors are beyond the focus of the present paper and are discussed elsewhere. Proteins that regulate GPCRs signaling such as GPCR kinases and arrestins, which are implicated in the control of food intake, regulation of insulin action, inflammation, adipogenesis, and other processes that are associated with weight gain and development of insulin resistance, are the focus of recent reviews $[100,101]$, so they are not discussed here.

The FAs-GPCRs receptors, which include the GPRs 40, $41,43,84,119$, and 120, present distinct ligand specificity and tissue distribution [102]. These receptors play a relevant role in physio- and pathological conditions [102]. Regarding their participation in the glucose metabolism, it has been 
demonstrated that their activation (at least, GPR40 and GPR119) directly stimulates insulin secretion by $\beta$-cells and protects these cells from gluco- and lipotoxicity (GPR40) $[103,104]$. Activation of FAs-GPCRs induces also the release of gut-derived hormones including glucagon-like peptide-1 (GLP-1) and glucose-dependent insulinotropic polypeptide (GIP) [105-109]. These latter two-gut-derived hormones not only modulate the gastrointestinal functions such as motility, but also the insulin secretion and food intake. In addition to these effects, FAs-GPCRs, mainly, GPR43, 84, and 120, present relevant effects in the inflammatory cell activation [102]. In this sense, activation of GPR120 and $\beta$-arrestin 2 by $\mathrm{n}-3$ fatty acids (docosahexaenoic and $\alpha$-linolenic acids) attenuates the production of TNF- $\alpha$, IL- 6 , and macrophage chemoattractant protein-1 (MCP-1, also known as CCL2). This anti-inflammatory effect seems to be important for the beneficial action of these fatty acids in the model of obesity induced by high-fat diet, preventing development of glucose intolerance, insulin resistance, and obesity [110].

Altogether the findings herein discussed highlight the importance of these receptors for glucose homeostasis, control of inflammatory cells activation, and food intake, processes that are linked through complexes interaction, which are not completely understood.

2.2. Histone Deacetylases. Histone deacetylase (HDAC) is a family of enzymes that together with the histone acetyltransferases (HATs) controls the degree of protein acetylation. Inhibition of HDAC activity by different compounds (e.g., short chain fatty acids such as butyrate, valproic acid, trichostatin $\mathrm{A}$, and other compounds) increases the acetylation of histone and nonhistone proteins including $\mathrm{NF} \kappa \mathrm{B}$, MyoD, p53, and N-FAT [111] and, consequently, affects gene expression and proteins activities leading to changes in different aspects of cell biology including cell motility, proliferation, differentiation, and apoptosis.

In addition to their well-known anti-inflammatory effects [112], other recent evidence has been obtained, which together strongly indicates HDAC as a target for novel therapies in insulin resistance and diabetes.

(i) Histone hyperacetylation has been associated with an increase in insulin expression and protection of $\beta$ cells against cytokine-induced apoptosis, as reviewed by Christensen et al. [113].

(ii) The isoforms 4, 5, and 9 of HDAC are associated with the development of $\beta$ and $\delta$ cells of the pancreas [48].

(iii) Oral administration of HDACi (ITF2357) reduced $\beta$ cells toxicity associated with streptozotocin administration. Additionally, the authors also showed that this HDACi protected islets from cytokineinduced toxicity and reduced production of $\mathrm{NO}$ and chemokines in islets [114];

(iv) Administration of sodium butyrate (diet supplementation or oral tributyrin (a prodrug of butyrate)) to high-fat fed mice attenuated body weight gain, improved lipid and glucose metabolism parameters, and inhibited the development of obesity-associated changes including activation of inflammatory pathways and hepatic steatosis $[115,116]$. Recently, it has been suggested that this effect of butyrate involves inhibition of HDAC 3 activity, an effect that leads to activation of PPAR- $\alpha$ and expression of FGF21, which stimulates lipid oxidation, triglyceride clearance, and energy expenditure [117];

(v) HDAC 6 knockout mice are protected from hyperglycemia, glucose intolerance, and insulin resistance secondary to chronic corticoid administration [118];

(vi) HDACi increases the number of $\mathrm{T}$ regulatory cells and their suppressive function, an effect that may be important in the context of adipose tissue inflammation $[119,120]$.

2.3. Peroxisome Proliferator-Activated Receptor- $\gamma$ (PPAR- $\gamma$ ). PPAR- $\gamma$ receptor activation has been shown to have significant effects on increasing insulin sensitivity in fat and muscle cells. It improves glucose metabolism and reduces inflammation (Figure 3) [121] and has a crucial role in adipocyte differentiation. PPAR- $\gamma$ is a nuclear receptor that acts as a transcription factor upon activation, by regulating the transcription and expression of specific genes such as adipokines. There are two isoforms of PPAR- $\gamma$ : PPAR- $\gamma 1$ and PPAR- $\gamma 2$. PPAR $-\gamma 1$ is expressed ubiquitously and PPAR- $\gamma 2$ is mainly expressed in adipocytes.

Several studies have demonstrated the anti-inflammatory activities of PPAR- $\gamma$. Inhibition of PPAR- $\gamma$ function by inflammatory cytokines may contribute to pathogenesis of many diseases such as insulin resistance, atherosclerosis, inflammation, and cancer cachexia [122-124]. Its inhibition by TNF- $\alpha$ is involved in inflammation pathogenesis characteristic of insulin resistance. Activation of serine kinases including IKK, ERK, JNK, and p38 may be involved in the TNF regulation of PPAR- $\gamma$ (Figure 3) (reviewed in [125]). IKK acts through at least two mechanisms: inhibition of PPAR- $\gamma$ expression [126] and activation of PPAR- $\gamma$ corepressor [127].

In macrophages, where PPAR gamma is also expressed, it inhibits TLR and IFN- $\gamma$ mediated inflammatory responses. In obesity, macrophages invade adipose tissue promoting the inflammation characteristic of insulin resistance [128]. Therefore, macrophage PPAR- $\gamma$ function gained considerable pharmacological interest [129]. Diet-induced obesity influences the state of adipose tissue macrophages from an M2-polarized state (that protects adipocytes from inflammation) to an M1 proinflammatory state. Studies have demonstrated that this obesity-induced phenotypic alteration of macrophage polarization is orchestrated by PPAR- $\gamma$ [130]. These researchers demonstrated that PPAR- $\gamma$ is required for the maturation of alternatively activated macrophages (M2 macrophages) by using mice with specific macrophage deletion of PPAR- $\gamma$.

Prolonged nutrient excess promotes the accumulation and activation of leukocytes in visceral adipose tissue and other tissues, leading to metabolic abnormalities such as insulin resistance. Cipolletta et al. [131] showed that PPAR- $y$ is involved with adipose tissue-specific lymphocyte 
accumulation and activation, leading to cell differentiation. $\mathrm{T}$ regulatory cells (Tregs) are a small subset of $\mathrm{T}$ lymphocytes, normally constituting only $5-20 \%$ of the CD $4^{+}$ compartment. These cells are thought to be one of the most critical defenses against excessive immune responses, avoiding autoimmunity, allergy, inflammation, infection, and tumorigenesis $[132,133]$. Typically, Tregs control other T cell populations, but can also influence the activities of innate immune system cells. Treg cells are characterized by highlevel expression of the forkhead/winged-helix transcription factor, Foxp3. Cipolletta et al. [131] have demonstrated that PPAR- $\gamma$ collaborates with Foxp 3 to impose on naive $\mathrm{CD} 4^{+} \mathrm{T}$ cells the characteristic of visceral adipose tissue Treg cells. In fact, Feuerer et al. [134] demonstrated that Treg cells with a unique phenotype were highly enriched in the abdominal fat of normal mice, but were specifically reduced at this tissue in an insulin-resistant model of obesity. Studies have suggested that adipokines may control $\mathrm{T}$ cell responses leading to Treg differentiation [135]. A recent study highlighted the negative effect of leptin on the proliferative capacity of Treg [136]. In fact, it is well demonstrated that obese subjects present low Treg cell number and adiponectin production and high leptin secretion [134]. Probably, PPAR- $\gamma$ is involved with adipokines regulation of lymphocyte differentiation in adipose tissue.

2.4. Toll-Like Receptors (TLRs). TLRs are transmembrane receptors that play a critical role in the detection of microbial infection and in the induction of inflammatory and immune responses against conserved microbial structures, called pathogen-associated molecular patterns [137]. Each member of TLR family recognizes a specific pathogen component which, upon activation, triggers a signaling cascade leading to cytokine production and adaptive immune response. Among the TLRs, TLR2 and TLR4 play a critical role in the pathogenesis of insulin resistance, diabetes, and atherosclerosis in both clinical and experimental conditions [138, 139].

$\mathrm{C} 3 \mathrm{H} / \mathrm{HeJ}$ mice with a mutation in TLR4 are protected against the development of high fat diet-induced obesity. In addition, these mice demonstrate decreased adiposity, increased oxygen consumption, a decreased respiratory exchange ratio, improved insulin sensitivity, and enhanced insulin-signaling capacity in adipose tissue, muscle, and liver. Moreover, in all these tissues, control mice fed a high-fat diet showed an increase in IkappaB kinase complex and cJun $\mathrm{NH}(2)$-terminal kinase activity, which is prevented in $\mathrm{C} 3 \mathrm{H} / \mathrm{HeJ}$ mice.

Studies in mice demonstrate that TLR-2 and TLR-4 activation and cytokine production stimulated by these receptors lead to the development of diabetes (Figure 3) $[140,141]$. More recently, TLR4 has been indicated as a molecular link between free fatty acids, inflammation, and the innate immune system. Dasu et al. [139] studied TLR2 and TLR4 mRNA and protein expression, their ligands, and intracellular signaling in monocytes of recently diagnosed type 2 diabetic patients and observed that there is significant elevation of TLR2 and TLR4 protein, mRNA, endogenous ligands, and cofactors which, together with hyperglycemia, contribute to the proinflammatory state of type 2 diabetes.

Koopet et al. [142] observed that TLR activation promotes upregulation of IL- 6 and MCP-1 release in isolated human adipocytes via specific activation of Erk. TLR-4 deficient mice had also markedly lower circulating concentrations of MCP-1 and much less NF-kB protein in nuclear extracts prepared from adipose tissue. In contrast, TLR-4 deficiency did not attenuate the induction of tumor necrosis factor-alpha (TNF- $\alpha$ ) or interleukin-6 (IL-6) expression in adipose tissue promoted by diet with high saturated fatty acids [143]. Nowadays, based on several studies it is clear that TLR4 inhibition is a pharmacologic tool to avoid inflammation in insulin resistance patients.

2.5. N-3 Fatty Acids-Derived Lipid Mediators. Arachidonic acid (n-6 fatty acid) serves as precursor of immune-active lipid mediators known as eicosanoids. Classes of eicosanoids include lipoxins, leukotrienes, and PGs, and their effects on the immune system have been extensively explored and reviewed [144].

First identified by Serhan et al. [145], resolvins are new mediators generated from n-3 fatty acids docosahexaenoic acid (DHA, C22:6n-3) and eicosapentaenoic (EPA, C20: $5 n-3)$ identified first in resolving inflammatory exudates and in tissues enriched with DHA. The names resolvin (resolution phase interaction products) and docosatrienes were given because these bioactive compounds demonstrate potent anti-inflammatory and immunoregulatory actions (Figure 3). These mediators prevented neutrophil entry to inflammation sites and cytokine production and reduced exudates in rats with experimental peritonitis [146]. The compounds derived from EPA carrying potent biological actions are named the E series and are denoted as resolvins of the E series. Those synthesized from DHA are resolvins of the 17S-D series that have immunoregulatory [145] and neuroprotective actions [147]. Protectin D1 (formerly known as neuroprotectin D1) is also generated from DHA [148]. These compounds are produced after acetylation of COX-2 by aspirin. In addition, aspirin treatment triggers the formation of 15-epimeric lipoxins, termed aspirin-triggered lipoxins, that also play a role in resolution of inflammation through inhibition of neutrophil tissue infiltration [146] and stimulation of macrophage phagocytosis of apoptotic neutrophils [149].

Studies demonstrate that n-3 fatty acid feeding promotes endogenous production of resolving D1 and 17-hydroxyDHA, a marker of resolvin biosynthesis, in adipose tissue of obese-diabetic mice [150]. Transgenic overexpression of fat-1, which encodes a desaturase enzyme that is able to convert $\omega-6$ to $\omega-3$ fatty acids, partially protects against obesity-induced insulin resistance in mice and is associated with an increase in the resolvin biosynthetic pathway marker 17-hydroxy-DHA [151]. These studies demonstrated that high-fat feeding results in a deficient endogenous resolvin and protectin biosynthesis and that these compounds are restored in fat- 1 transgenic mice.

Horrillo et al. [152] provided evidence that adipose tissue expresses all the enzymes necessary for the formation of 


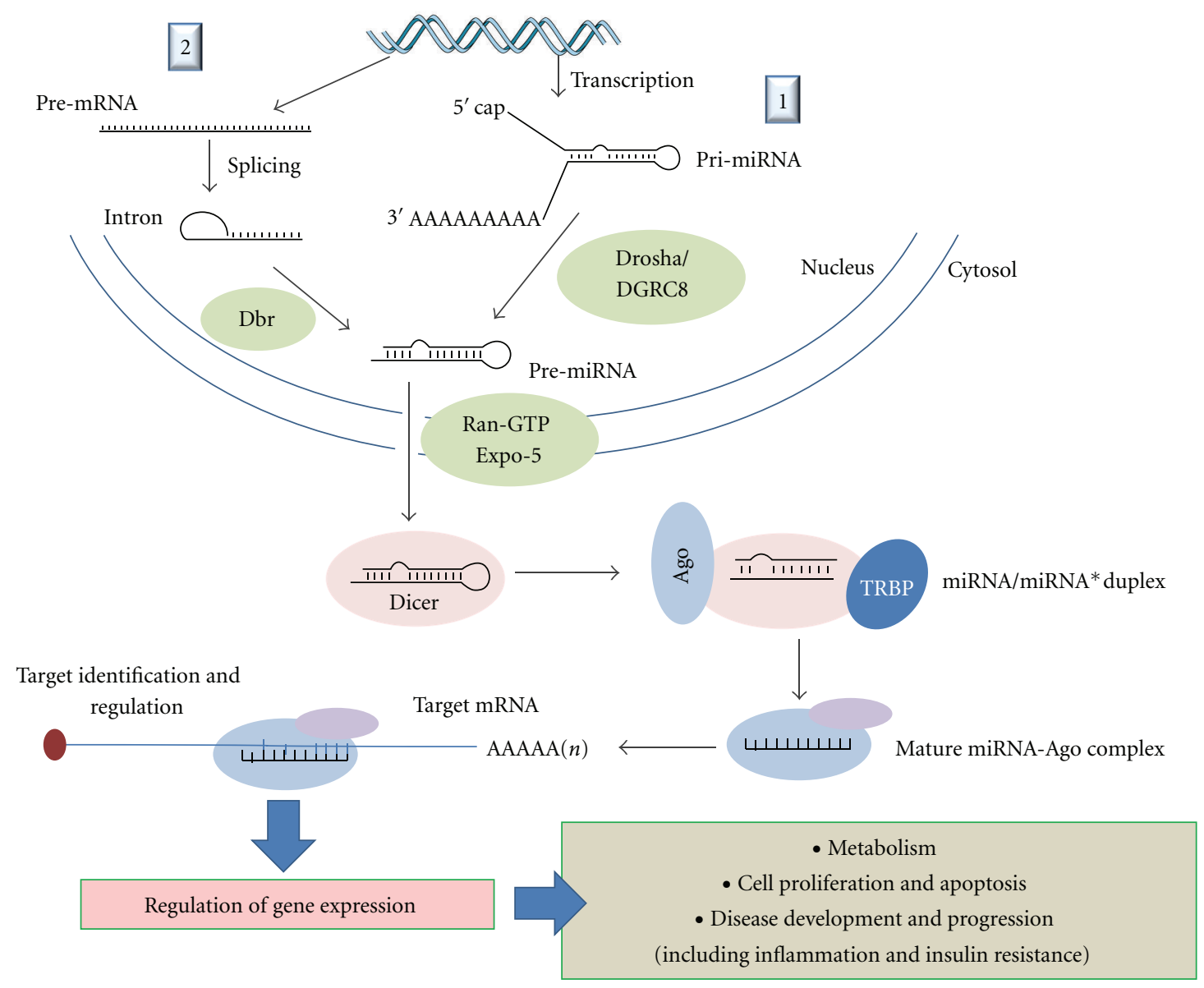

FIgURE 4: MicroRNA (miRNA) biogenesis and gene expression control in human cells. (1) Canonical pathway produces pre-miRNA by Drosha/DGCR8 cleavage of pri-miRNA. (2) Noncanonical pathway mirtrons are produced by spliced introns debranched by debranching enzyme (Dbr), after which they fold into pre-miRNA hairpins. Pre-miRNA hairpins are exported from the nucleus to cytosol by exportin-5 (Expo-5) and cleaved by Dicer to produce 22 nucleotides RNA duplexes. One strand of the duplex is transferred to Argonaute complex (Ago) and guided to base-pair with its target mRNA throughout its seed sequence. TRBP: tar-RNA binding protein.

bioactive lipid mediators derived from both omega- 6 and omega-3-PUFAs. In ob/ob mice DHA significantly increased adipose tissue levels of adiponectin, which alleviated hepatic steatosis and insulin resistance [150]. Recent findings indicate also that DHA (at micromolar concentrations) and resolvin D1 (at nanomolar concentrations) consistently decrease M1 macrophage activation in adipose tissue and increase M2 cells. These effects are related to stimulation of arginase 1 expression and attenuation of IFN $\gamma /$ LPS-induced Th1 cytokine secretion [153].

Hellmann et al. [154] suggested that stimulation of the inflammation resolution with the endogenous proresolving mediator resolving D1 provides a novel therapeutic strategy for treating obesity-induced diabetes. The authors observed that in leptin-receptor deficient mouse resolvin D1 prevents the accumulation of macrophages in adipose tissue and restores systemic insulin sensitivity. Notably, these inflammation-resolving factors are important tools to decrease adipose tissue inflammation that is common in insulin resistance.
2.6. MicroRNAs. MicroRNAs (miRNAs or miRs) are short noncoding RNAs that have been demonstrated to be master regulators of the cellular transcriptome and proteome [155-157]. Regulatory miRNAs bind to the complementary segments within $3^{\prime}$-untranslated region ( $3^{\prime}$ UTR) of target transcripts through Watson-Crick base pairing, causing translational inhibition or mRNA cleavage and suppression of gene expression. Over 1000 miRNAs have been identified in the human genome, which are estimated to regulate thousands of protein-coding genes $[158,159]$. There is also increasing experimental evidence that miRNAs are involved in the control of several critical biological processes such as metabolism, cell proliferation, apoptosis, and disease development and progression [160-163].

Single-stranded mature miRNAs with 20-24 nucleotides in length are derived from genomically encoded sequences through transcription and complex mRNA processing. Change in gene expression or processing in dysfunctional or abnormal cells or tissues leads to an altered miRNA expression level. Figure 4 summarizes biogenesis and gene 
expression control by miRNAs. Profile of these molecules may be used as biomarkers for classifying human diseases and disease status $[162,164,165]$.

Recent studies have observed an association between specific miRNAs and insulin resistance [166, 167], supporting the fact that miRNAs may play a role in the pathological development of type 2 diabetes mellitus and leading also to the hypothesis that miRNAs may represent a new class of glucose metabolism regulators with therapeutic potential for improving insulin sensitivity in peripheral tissues. Supporting this idea, Frost and Olson [168] have demonstrated that global and pancreas-specific overexpression of the miRNA Let-7 in mice results in impaired glucose tolerance and reduced glucose-induced pancreatic insulin secretion. Pharmacological inhibition of the miRNA Let-7 family with specific anti-miR was sufficient to prevent and treat impaired glucose tolerance in diet-induced obesity mice, at least in part, by improving insulin sensitivity in liver and muscle. In addition, miRNA Let-7 was able to block glucoseinduced insulin secretion from the pancreas, suggesting that knockdown of this miRNA also might improve pancreatic $\beta$ cell function.

A role of the heart in systemic metabolic control and the involvement of the heart-specific microRNA, miR-208a, as potential therapeutic target for metabolic disorder have been proposed. Impaired metabolism of energy-providing substrates and myocardial lipid accumulation are early abnormalities in obese and insulin-resistant individuals [169]. Grueter et al. [170] have shown that MED13, a subunit of the Mediator complex, controls transcription by thyroid hormone and other functions of nuclear hormone receptors in heart, controlling metabolic homeostasis and energy expenditure in mice. They have also shown that miR-208a, a heart-specific miRNA encoded by an intron of the cardiac-specific $\alpha$-myosin heavy-chain (MHC) gene, negatively regulates MED13 expression. Elevated cardiac expression of MED13 or pharmacologic inhibition of miR208a in mice led to resistance to high-fat diet-induced obesity and improved systemic insulin sensitivity and glucose tolerance in mice. Conversely, genetic deletion of MED13 specifically in cardiomyocytes enhanced obesity in response to high-fat diet and exacerbated metabolic syndrome [170].

As discussed previously, inflammation and oxidative stress participate in the propagation and development of obesity and associated metabolic disorders associated to insulin resistance. Maladaptive production of various adipokines (e.g., adiponectin, resistin, visfatin, and leptin), migration of monocytes, and subsequent transformation into macrophages within affected tissues are key factors in the self-perpetuating inflammation associated with metabolic disorders [171, 172]. In particular, plasma levels of adiponectin are significantly lower in obese individuals and have been associated with inflammation, insulin resistance, and cardiovascular disease. The involvement of miRs in the protective effects of adiponectin has been recently evaluated. Hulsmans et al. [173] identified miR-146b-5p as a downregulated miR in monocytes of obese subjects with targets in the IRAK/NFkB-related gene cluster. They identified obesityassociated low levels of globular adiponectin as cause of the decrease in miR-146b-5p. The role of miR-146b-5p in the protection against inflammation was further supported by the finding that, after sequestration of miR-146b-5p, the cells lost their potency to raise their anti-inflammatory action in response to high levels of adiponectin.

A possible role of miR-107 in regulating the inflammatory process that might lead to type 2 diabetes mellitus has been proposed by Foley and O'Neill [174]. Because the TLR4 (LPS receptor) has been shown to downregulate miR-107 in activated macrophages located in adipose tissue [175], and miR-107 has been demonstrated to be dysregulated in murine and rodent models of obesity and insulin resistance, respectively [176-178], it has been suggested that miR-107 may be the link between obesity, inflammation, and insulin resistance. The authors hypothesize that decreased miR-107 by TLR4 is required to limit proinflammatory signaling pathways, since this effect will stabilize Caveolin-1, blocking the TLR4 pathway by displacement of MYD88. Decreased miR-107 is an attempt to increase insulin sensitivity in the resolution phase of inflammation. A defect in this process, particularly in the ability of TLR4 to decrease miR-107, could therefore promote inflammation and type 2 diabetes mellitus. Further investigations are warranted to assess this hypothesis. An interesting model would be transgenic mice, in which we could manipulate miR-107 in vivo and pharmacologically inhibit miR-107.

\section{Concluding Remarks}

The discovery and identification of new biomarkers involved in the pathogenesis of chronic inflammation and insulin resistance have been fundamental to understanding how these processes work and to direct further studies for the prevention or treatment of related disorders. Particularly, these discoveries have aided to identify new target genes, lipids, proteins, and other metabolites involved in the development or severity of chronic diseases, for example, obesity, type 2 diabetes mellitus, metabolic syndrome, cardiovascular diseases, cancer, dyslipidemia, and cancer. Probably, with the help of new tools and advanced methodologies, we will have a better characterization and understanding of the mechanisms and mediators involved in the different inflammatory and insulin resistance conditions, addressing further biotechnological studies for the development of new potential clinical therapies and interventions.

\section{Acknowledgments}

This study was supported by grants from São Paulo Research Foundation (FAPESP), Coordination for the Improvement of Higher Level Personnel (CAPES), National Council for Scientific and Technological Development (CNPq)/National Institute of Science and Technology in Obesity and Diabetes (INOD), Center of Lipid Research and Education (CLEaR), and Dean's Office for Research/University of São Paulo. A. Rodrigues is a recipient of fellowship from FAPESP (2011/05876-6). 


\section{References}

[1] X. J. Sun, P. Rothenberg, C. R. Kahn et al., "Structure of the insulin receptor substrate IRS-1 defines a unique signal transduction protein," Nature, vol. 352, no. 6330, pp. 73-77, 1991.

[2] D. J. Burks and M. F. White, "IRS proteins and beta-cell function,” Diabetes, vol. 50, pp. S140-S145, 2001.

[3] S. Durmuş Tekir, P. Ümit, A. Eren Toku, and K. O. Ülgen, "Reconstruction of protein-protein interaction network of insulin signaling in Homo sapiens," Journal of Biomedicine and Biotechnology, vol. 2010, Article ID 690925, 7 pages, 2010.

[4] I. Hirayama, H. Tamemoto, H. Yokota et al., "Insulin receptor-related receptor is expressed in pancreatic $\beta$-cells and stimulates tyrosine phosphorylation of insulin receptor substrate-1 and- 2," Diabetes, vol. 48, no. 6, pp. 1237-1244, 2000.

[5] M. Paris, C. Bernard-Kargar, J. Vilar, N. Kassis, and A. Ktorza, "Role of glucose in IRS signaling in rat pancreatic islets: specific effects and interplay with insulin," Experimental Diabesity Research, vol. 5, no. 4, pp. 257-263, 2004.

[6] A. C. Thirone, C. Huang, and A. Klip, "Tissue-specific roles of IRS proteins in insulin signaling and glucose transport," Trends in Endocrinology and Metabolism, vol. 17, no. 2, pp. 72-78, 2006.

[7] A. R. Saltiel and C. R. Kahn, "Insulin signalling and the regulation of glucose and lipid metabolism," Nature, vol. 414, no. 6865, pp. 799-806, 2001.

[8] L. M. Furtado, R. Somwar, G. Sweeney, W. Niu, and A. Klip, "Activation of the glucose transporter GLUT4 by insulin," Biochemistry and Cell Biology, vol. 80, no. 5, pp. 569-578, 2002.

[9] L. Chang, S. H. Chiang, and A. R. Saltiel, "Insulin signaling and the regulation of glucose transport," Molecular Medicine, vol. 10, no. 7-12, pp. 65-71, 2004.

[10] F. S. L. Thong, C. B. Dugani, and A. Klip, "Turning signals on and off: GLUT4 traffic in the insulin-signaling highway," Physiology, no. 4, pp. 271-284, 2005.

[11] M. D. Sharma, A. J. Garber, and J. A. Farmer, "Role of insulin signaling in maintaining energy homeostasis," Endocrine Practice, vol. 14, no. 3, pp. 373-380, 2008.

[12] C. A. Baumann, V. Ribon, M. Kanzaki et al., "CAP defines a second signalling pathway required for insulin-stimulated glucose transport," Nature, vol. 407, no. 6801, pp. 202-207, 2000.

[13] J. Liu, A. Kimura, C. A. Baumann, and A. R. Saltiel, "APS facilitates c-Cbl tyrosine phosphorylation and GLUT4 translocation in response to insulin in 3T3-L1 adipocytes," Molecular and Cellular Biology, vol. 22, no. 11, pp. 3599-3609, 2002.

[14] J. Hu, J. Liu, R. Ghirlando, A. R. Saltiel, and S. R. Hubbard, "Structural basis for recruitment of the adaptor protein APS to the activated insulin receptor," Molecular Cell, vol. 12, no. 6, pp. 1379-1389, 2003.

[15] P. Mitra, X. Zheng, and M. P. Czech, "RNAi-based analysis of CAP, Cbl, and CrkII function in the regulation of GLUT4 by insulin," The Journal of Biological Chemistry, vol. 279, no. 36, pp. 37431-37435, 2004.

[16] J. Liu, S. M. DeYoung, M. Zhang, L. H. Dold, and A. R. Saltiel, "The stomatin/prohibitin/flotillin/HflK/C domain of flotillin-1 contains distinct sequences that direct plasma membrane localization and protein interactions in $3 \mathrm{~T} 3-\mathrm{L} 1$ adipocytes," The Journal of Biological Chemistry, vol. 280, no. 16, pp. 16125-16134, 2005.

[17] S. E. Egan, B. W. Giddings, M. W. Brooks, L. Buday, A. M. Sizeland, and R. A. Weinberg, "Association of Sos Ras exchange protein with Grb2 is implicated in tyrosine kinase signal transduction and transformation," Nature, vol. 362, no. 6424, pp. 45-51, 1993.

[18] P. Chardin, J. H. Camonis, N. W. Gale et al., "Human Sos1: a guanine nucleotide exchange factor for Ras that binds to GRB2,” Science, vol. 260, no. 5112, pp. 1338-1343, 1993.

[19] E. Y. Skolnik, A. Batzer, N. Li et al., "The function of GRB2 in linking the insulin receptor to Ras signaling pathways," Science, vol. 260, no. 5116, pp. 1953-1955, 1993.

[20] V. Baron and E. Van Obberghen, "Mechanism of insulin action," Comptes Rendus des Seances de la Societe de Biologie et de Ses Filiales, vol. 189, no. 1, pp. 25-41, 1995.

[21] M. Combettes-Souverain and T. Issad, "Molecular basis of insulin action," Diabetes and Metabolism, vol. 24, no. 6, pp. 477-489, 1998.

[22] Y. Yano, Y. Sumida, C. F. Benzing, F. W. Robinson, and T. Kono, "Primary sites of actions of staurosporine and H-7 in the cascade of insulin action to glucose transport in rat adipocytes," Biochimica et Biophysica Acta, vol. 1176, no. 3, pp. 327-332, 1993.

[23] G. Sweeney, R. Somwar, T. Ramlal, A. Volchuk, A. Ueyama, and A. Klip, "An inhibitor of p38 mitogen-activated protein kinase prevents insulin- stimulated glucose transport but not glucose transporter translocation in 3T3-L1 adipocytes and L6 myotubes," The Journal of Biological Chemistry, vol. 274, no. 15, pp. 10071-10078, 1999.

[24] R. Somwar, D. Y. Kim, G. Sweeney et al., "GLUT4 translocation precedes the stimulation of glucose uptake by insulin in muscle cells: potential activation of GLUT4 via p38 mitogenactivated protein kinase," Biochemical Journal, vol. 359, no. 3, pp. 639-649, 2001.

[25] F. H. Nystrom and M. Quon, "Insulin signalling: metabolic pathways and mechanisms for specificity," Cellular Signalling, vol. 11 , no. 8, pp. 563-574, 1999.

[26] G. Liu and C. M. Rondinone, "JNK: bridging the insulin signaling and inflammatory pathway," Current Opinion in Investigational Drugs, vol. 6, no. 10, pp. 979-987, 2005.

[27] S. Prudente, E. Morini, and V. Trischitta, "Insulin signaling regulating genes: effect on T2DM and cardiovascular risk," Nature Reviews Endocrinology, vol. 5, no. 12, pp. 682-693, 2009.

[28] J. L. Rains and S. K. Jain, "Oxidative stress, insulin signaling, and diabetes," Free Radical Biology and Medicine, vol. 50, no. 5, pp. 567-575, 2011.

[29] M. A. Abdul-Ghani and R. A. Defronzo, "Pathogenesis of insulin resistance in skeletal muscle," Journal of Biomedicine and Biotechnology, vol. 2010, Article ID 476279, 19 pages, 2010.

[30] A. Kontrogianni-Konstantopoulos, G. Benian, and H. Granzier, "Advances in muscle physiology and pathophysiology," Journal of Biomedicine and Biotechnology, vol. 2010, Article ID 780417, 1 pages, 2010.

[31] M. Di Carlo, P. Picone, R. Carrotta, D. Giacomazza, and P. L. San Biagio, "Insulin promotes survival of amyloid-beta oligomers neuroblastoma damaged cells via caspase 9 inhibition and Hsp70 upregulation," Journal of Biomedicine and Biotechnology, vol. 2010, Article ID 147835, 8 pages, 2010.

[32] M. Peppa, C. Koliaki, P. Nikolopoulos, and S. A. Raptis, "Skeletal muscle insulin resistance in endocrine disease," 
Journal of Biomedicine and Biotechnology, vol. 2010, Article ID 527850, 13 pages, 2010.

[33] A. Kontrogianni-Konstantopoulos, G. Benian, and H. Granzier, "Advances in muscle physiology and pathophysiology 2011," Journal of Biomedicine and Biotechnology, vol. 2012, Article ID 930836, 1 pages, 2012.

[34] S. M. Hirabara, L. R. Silveira, F. Abdulkader, C. R. O. Carvalho, J. Procopio, and R. Curi, "Time-dependent effects of fatty acids on skeletal muscle metabolism," Journal of Cellular Physiology, vol. 210, no. 1, pp. 7-15, 2007.

[35] L. R. Silveira, J. Fiamoncini, S. M. Hirabara et al., "Updating the effects of fatty acids on skeletal muscle," Journal of Cellular Physiology, vol. 217, no. 1, pp. 1-12, 2008.

[36] S. M. Hirabara, R. Curi, and P. Maechler, "Saturated fatty acid-induced insulin resistance is associated with mitochondrial dysfunction in skeletal muscle cells," Journal of Cellular Physiology, vol. 222, no. 1, pp. 187-194, 2010.

[37] A. R. Martins, R. T. Nachbar, R. Gorjao et al., "Mechanisms underlying skeletal muscle insulin resistance induced by fatty acids: importance of the mitochondrial function," Lipids in Health and Disease, vol. 11, article 30, 2012.

[38] G. I. Shulman, "Cellular mechanisms of insulin resistance," The Journal of Clinical Investigation, vol. 106, no. 2, pp. 171176, 2000.

[39] M. Roden, "How free fatty acids inhibit glucose utilization in human skeletal muscle," News in Physiological Sciences, vol. 19, no. 3, pp. 92-96, 2004.

[40] C. Yu, Y. Chen, G. W. Cline et al., "Mechanism by which fatty acids inhibit insulin activation of insulin receptor substrate1 (IRS-1)-associated phosphatidylinositol 3-kinase activity in muscle," The Journal of Biological Chemistry, vol. 277, no. 52, pp. 50230-50236, 2002.

[41] P. Newsholme, E. P. Haber, S. M. Hirabara et al., "Diabetes associated cell stress and dysfunction: role of mitochondrial and non-mitochondrial ROS production and activity," Journal of Physiology, vol. 583, no. 1, pp. 9-24, 2007.

[42] P. J. Randle, P. B. Garland, C. N. Hales, and E. A. Newsholme, "The glucose fatty-acid cycle. Its role in insulin sensitivity and the metabolic disturbances of diabetes mellitus," The Lancet, vol. 281, no. 7285, pp. 785-789, 1963.

[43] M. Roden, T. B. Price, G. Perseghin et al., "Mechanism of free fatty acid-induced insulin resistance in humans," The Journal of Clinical Investigation, vol. 97, no. 12, pp. 2859-2865, 1996.

[44] M. E. Griffin, M. J. Marcucci, G. W. Cline et al., "Free fatty acid-induced insulin resistance is associated with activation of protein kinase $\mathrm{C} \theta$ and alterations in the insulin signaling cascade," Diabetes, vol. 48, no. 6, pp. 1270-1274, 2000.

[45] S. Massao Hirabara, C. R. De Oliveira Carvalho, J. R. Mendonça, E. Piltcher Haber, L. C. Fernandes, and R. Curi, "Palmitate acutely raises glycogen synthesis in rat soleus muscle by a mechanism that requires its metabolization (Randle cycle)," FEBS Letters, vol. 541, no. 1-3, pp. 109-114, 2003.

[46] M. A. Carvalho-Filho, M. Ueno, S. M. Hirabara et al., "Snitrosation of the insulin receptor, insulin receptor substrate 1 , and protein kinase B/Akt: a novel mechanism of insulin resistance," Diabetes, vol. 54, no. 4, pp. 959-967, 2005.

[47] A. Brehm, M. Krssak, A. I. Schmid, P. Nowotny, W. Waldhäusl, and M. Roden, "Increased lipid availability impairs insulin-stimulated ATP synthesis in human skeletal muscle," Diabetes, vol. 55, no. 1, pp. 136-140, 2006.

[48] O. Lenoir, K. Flosseau, F. X. Ma et al., "Specific control of pancreatic endocrine $\beta$ - and $\delta$-cell mass by class IIa histone deacetylases HDAC4, HDAC5, and HDAC9," Diabetes, vol. 60, no. 11, pp. 2861-2871, 2011.

[49] R. Rajendran, R. Garva, M. Krstic-Demonacos, and C. Demonacos, "Sirtuins: molecular traffic lights in the crossroad of oxidative stress, chromatin remodeling, and transcription," Journal of Biomedicine and Biotechnology, vol. 2011, Article ID 368276, 17 pages, 2011.

[50] M. Murata, R. Thanan, N. Ma, and S. Kawanishi, "Role of nitrative and oxidative DNA damage in inflammation-related carcinogenesis," Journal of Biomedicine and Biotechnology, vol. 2012, Article ID 623019, 11 pages, 2012.

[51] N. Bashan, J. Kovsan, I. Kachko, H. Ovadia, and A. Rudich, "Positive and negative regulation of insulin signaling by reactive oxygen and nitrogen species," Physiological Reviews, vol. 89, no. 1, pp. 27-71, 2009.

[52] L. Zhang, S. Haraguchi, T. Koda, K. Hashimoto, and A. Nakagawara, "Muscle atrophy and motor neuron degeneration in human NEDL1 transgenic mice," Journal of Biomedicine and Biotechnology, vol. 2011, Article ID 831092, 7 pages, 2011.

[53] J. L. Evans, J. J. Lin, and I. D. Goldfine, "Novel approach to treat insulin resistance, type 2 diabetes, and the metabolic syndrome: simultaneous activation of PPARalpha, PPARgamma, and PPARdelta," Current Diabetes Reviews, vol. 1, no. 3, pp. 299-307, 2005.

[54] E. J. Henriksen, M. K. Diamond-Stanic, and E. M. Marchionne, "Oxidative stress and the etiology of insulin resistance and type 2 diabetes," Free Radical Biology and Medicine, vol. 51, no. 5, pp. 993-999, 2011.

[55] J. H. Lim, J. I. Lee, Y. H. Suh, W. Kim, J. H. Song, and M. H. Jung, "Mitochondrial dysfunction induces aberrant insulin signalling and glucose utilisation in murine $\mathrm{C} 2 \mathrm{C} 12$ myotube cells," Diabetologia, vol. 49, no. 8, pp. 1924-1936, 2006.

[56] W. X. Guo, Q. N. Pye, K. S. Williamson et al., "Mitochondrial dysfunction in choline deficiency-induced apoptosis in cultured rat hepatocytes," Free Radical Biology and Medicine, vol. 39, no. 5, pp. 641-650, 2005.

[57] J. P. Wallace, B. Johnson, J. Padilla, and K. Mather, "Postprandial lipaemia, oxidative stress and endothelial function: a review," International Journal of Clinical Practice, vol. 64, no. 3, pp. 389-403, 2010.

[58] R. Medzhitov, "Origin and physiological roles of inflammation,” Nature, vol. 454, no. 7203, pp. 428-435, 2008.

[59] C. N. Lumeng and A. R. Saltiel, "Inflammatory links between obesity and metabolic disease," The Journal of Clinical Investigation, vol. 121, no. 6, pp. 2111-2117, 2011.

[60] G. S. Hotamisligil, "Inflammation and metabolic disorders," Nature, vol. 444, no. 7121, pp. 860-867, 2006.

[61] K. Sun, C. M. Kusminski, and P. E. Scherer, "Adipose tissue remodeling and obesity," The Journal of Clinical Investigation, vol. 121, no. 6, pp. 2094-2101, 2011.

[62] I. Mothe-Satney, C. Filloux, H. Amghar et al., "Adipocytes secrete leukotrienes: contribution to obesity-associated inflammation and insulin resistance in mice," Diabetes, vol. 61, no. 9, pp. 2311-2319, 2012.

[63] J. Kurokaw, H. Nagano, O. Ohara et al., "Apoptosis inhibitor of macrophage (AIM) is required for obesity-associated recruitment of inflammatory macrophages into adipose tissue," Proceedings of the National Academy of Sciences of the United States of America, vol. 108, no. 29, pp. 12072-12077, 2011.

[64] N. Lanthier, O. Molendi-Coste, Y. Horsmans, N. Van Rooijen, P. D. Cani, and I. A. Leclercq, "Kupffer cell activation is a 
causal factor for hepatic insulin resistance," American Journal of Physiology, vol. 298, no. 1, pp. G107-G116, 2010.

[65] S. Nishimura, I. Manabe, M. Nagasaki et al., "CD8 ${ }^{+}$effector $\mathrm{T}$ cells contribute to macrophage recruitment and adipose tissue inflammation in obesity," Nature Medicine, vol. 15, no. 8, pp. 914-920, 2009.

[66] M. Feuerer, L. Herrero, D. Cipolletta et al., "Lean, but not obese, fat is enriched for a unique population of regulatory $\mathrm{T}$ cells that affect metabolic parameters," Nature Medicine, vol. 15, no. 8, pp. 930-939, 2009.

[67] V. Z. Rocha, E. J. Folco, G. Sukhova et al., "Interferon- $\gamma$, a Th1 cytokine, regulates fat inflammation: a role for adaptive immunity in obesity," Circulation Research, vol. 103, no. 5, pp. 467-476, 2008.

[68] A. Bertola, T. Ciucci, D. Rousseau et al., "Identification of adipose tissue dendritic cells correlated with obesityassociated insulin-resistance and inducing Th17 responses in mice and patients," Diabetes, vol. 61, no. 9, pp. 2238-2247, 2012.

[69] H. M. Davis, D. C. Carpenter, J. M. Stahl, W. Zhang, W. P. Hynicka, and D. E. Griswold, "Human granulocyte CD11b expression as a pharmacodynamic biomarker of inflammation," Journal of Immunological Methods, vol. 240, no. 1-2, pp. 125-132, 2000.

[70] G. S. Hotamisligil, N. S. Shargill, and B. M. Spiegelman, "Adipose expression of tumor necrosis factor- $\alpha$ : direct role in obesity-linked insulin resistance," Science, vol. 259, no. 5091, pp. 87-91, 1993.

[71] T. Haruta, T. Uno, J. Kawahara et al., "A rapamycin-sensitive pathway down-regulates insulin signaling via phosphorylation and proteasomal degradation of insulin receptor substrate-1," Molecular Endocrinology, vol. 14, no. 6, pp. 783794, 2000.

[72] P. Gual, Y. Le Marchand-Brustel, and J. F. Tanti, "Positive and negative regulation of insulin signaling through IRS-1 phosphorylation," Biochimie, vol. 87, no. 1, pp. 99-109, 2005.

[73] K. Hiratani, T. Haruta, A. Tani, J. Kawahara, I. Usui, and M. Kobayashi, "Roles of mTOR and JNK in serine phosphorylation, translocation, and degradation of IRS-1," Biochemical and Biophysical Research Communications, vol. 335, no. 3, pp. 836-842, 2005.

[74] D. M. L. Tsukumo, M. A. Carvalho-Filho, J. B. C. Carvalheira et al., "Loss-of-function mutation in toll-like receptor 4 prevents diet-induced obesity and insulin resistance," Diabetes, vol. 56, no. 8, pp. 1986-1998, 2007.

[75] F. Wu, Y. Liu, X. Lv, X. Miao, Y. Sun, and W. Yu, "Small interference RNA targeting TLR4 gene effectively attenuates pulmonary inflammation in a rat model," Journal of Biomedicine and Biotechnology, vol. 2012, Article ID 406435, 8 pages, 2012.

[76] J. Hirosumi, G. Tuncman, L. Chang et al., "A central, role for JNK in obesity and insulin resistance," Nature, vol. 420, no. 6913, pp. 333-336, 2002.

[77] H. Kaneto, Y. Nakatani, D. Kawamori et al., "Role of oxidative stress, endoplasmic reticulum stress, and c-Jun N-terminal kinase in pancreatic $\beta$-cell dysfunction and insulin resistance," International Journal of Biochemistry and Cell Biology, vol. 38, no. 5-6, pp. 782-793, 2006.

[78] G. Solinas, W. Naugler, F. Galimi, M. S. Lee, and M. Karin, "Saturated fatty acids inhibit induction of insulin gene transcription by JNK-mediated phosphorylation of insulinreceptor substrates," Proceedings of the National Academy of
Sciences of the United States of America, vol. 103, no. 44, pp. 16454-16459, 2006.

[79] L. Håversen, K. N. Danielsson, L. Fogelstrand, and O. Wiklund, "Induction of proinflammatory cytokines by long-chain saturated fatty acids in human macrophages," Atherosclerosis, vol. 202, no. 2, pp. 382-393, 2009.

[80] H. Wen, D. Gris, Y. Lei et al., "Fatty acid-induced NLRP3ASC inflammasome activation interferes with insulin signaling," Nature Immunology, vol. 12, no. 5, pp. 408-415, 2011.

[81] D. K. Coletta and L. J. Mandarino, "Mitochondrial dysfunction and insulin resistance from the outside in: extracellular matrix, the cytoskeleton, and mitochondria," vol. 301, no. 5, pp. E749-E755, 2011.

[82] R. C. Bunn, G. E. Cockrell, Y. Ou, K. M. Thrailkill, C. K. Lumpkin, and J. L. Fowlkes, "Palmitate and insulin synergistically induce IL-6 expression in human monocytes," Cardiovascular Diabetology, vol. 9, article 73, 2010.

[83] C. Ji, X. Chen, C. Gao et al., "IL-6 induces lipolysis and mitochondrial dysfunction, but does not affect insulinmediated glucose transport in 3T3-L1 adipocytes," Journal of Bioenergetics and Biomembranes, vol. 43, no. 4, pp. 367-375, 2011.

[84] R. Yasuhara, Y. Miyamoto, T. Akaike et al., "Interleukin$1 \beta$ induces death in chondrocyte-like ATDC5 cells through mitochondrial dysfunction and energy depletion in a reactive nitrogen and oxygen species-dependent manner," Biochemical Journal, vol. 389, no. 2, pp. 315-323, 2005.

[85] F. Ofei, S. Hurel, J. Newkirk, M. Sopwith, and R. Taylor, "Effects of an engineered human anti-TNF- $\alpha$ antibody (CDP571) on insulin sensitivity and glycemic control in patients with NIDDM," Diabetes, vol. 45, no. 3, pp. 881-885, 1996.

[86] L. E. Bernstein, J. Berry, S. Kim, B. Canavan, and S. K. Grinspoon, "Effects of etanercept in patients with the metabolic syndrome," Archives of Internal Medicine, vol. 166, no. 8, pp. 902-908, 2006.

[87] H. Dominguez, H. Storgaard, C. Rask-Madsen et al., "Metabolic and vascular effects of tumor necrosis factor$\alpha$ blockade with etanercept in obese patients with type 2 diabetes," Journal of Vascular Research, vol. 42, no. 6, pp. 517525, 2005.

[88] N. Paquot, M. J. Castillo, P. J. Lefèbvre, and A. J. Scheen, "No increased insulin sensitivity after a single intravenous administration of a recombinant human tumor necrosis factor receptor: Fc fusion protein in obese insulin-resistant patients," Journal of Clinical Endocrinology and Metabolism, vol. 85, no. 3, pp. 1316-1319, 2000.

[89] T. C. Wascher, J. H. N. Lindeman, H. Sourij, T. Kooistra, G. Pacini, and M. Roden, "Chronic TNF- $\alpha$ neutralization does not improve insulin resistance or endothelial function in "healthy" men with metabolic syndrome," Molecular Medicine, vol. 17, no. 3-4, pp. 189-193, 2011.

[90] M. A. Gonzalez-Gay, J. M. De Matias, C. Gonzalez-Juanatey et al., "Anti-tumor necrosis factor- $\alpha$ blockade improves insulin resistance in patients with rheumatoid arthritis," Clinical and Experimental Rheumatology, vol. 24, no. 1, pp. 83-86, 2006.

[91] M. A. Gonzalez-Gay, C. Gonzalez-Juanatey, T. R. VazquezRodriguez, J. A. Miranda-Filloy, and J. Llorca, "Insulin resistance in rheumatoid arthritis: the impact of the anti-TNF$\alpha$ therapy: annals of the New York Academy of Sciences," Annals of the New York Academy of Sciences, vol. 1193, pp. 153-159, 2010. 
[92] B. Seriolo, S. Paolino, C. Ferrone, and M. Cutolo, "Impact of long-term anti-TNF- $\alpha$ treatment on insulin resistance in patients with rheumatoid arthritis," Clinical and Experimental Rheumatology, vol. 26, no. 1, article 159, 2008.

[93] L. S. Tam, B. Tomlinson, T. T. Chu, T. K. Li, and E. K. Li, "Impact of TNF inhibition on insulin resistance and lipids levels in patients with rheumatoid arthritis," Clinical Rheumatology, vol. 26, no. 9, pp. 1495-1498, 2007.

[94] J. A. Miranda-Filloy, J. Llorca, B. Carnero-Lopez, C. Gonzalez-Juanatey, R. Blanco, and M. A. Gonzalez-Gay, "TNFalpha antagonist therapy improves insulin sensitivity in non-diabetic ankylosing spondylitis patients," Clinical and Experimental Rheumatology. In press.

[95] I. Stagakis, G. Bertsias, S. Karvounaris et al., "Anti-tumor necrosis factor therapy improves insulin resistance, beta cell function and insulin signaling in active rheumatoid arthritis patients with high insulin resistance," Arthritis Research and Therapy, vol. 14, no. 3, article 141, 2012.

[96] P. M. Ridker, T. Thuren, A. Zalewski, and P. Libby, "Interleukin- $1 \beta$ inhibition and the prevention of recurrent cardiovascular events: rationale and Design of the Canakinumab Anti-inflammatory Thrombosis Outcomes Study (CANTOS)," American Heart Journal, vol. 162, no. 4, pp. 597-605, 2011.

[97] H. Cho, S. C. Black, D. Looper et al., "Pharmacological characterization of a small molecule inhibitor of c-Jun kinase," American Journal of Physiology, vol. 295, no. 5, pp. E1142-E1151, 2008.

[98] J. L. Stebbins, S. K. De, T. Machleidt et al., "Identification of a new JNK inhibitor targeting the JNK-JIP interaction site," Proceedings of the National Academy of Sciences of the United States of America, vol. 105, no. 43, pp. 16809-16813, 2008.

[99] J. L. Stebbins, S. K. De, P. Pavlickova et al., "Design and characterization of a potent and selective dual ATP- and substrate-competitive subnanomolar bidentate c-Jun $\mathrm{N}$ terminal kinase (JNK) inhibitor," Journal of Medicinal Chemistry, vol. 54, no. 18, pp. 6206-6214, 2011.

[100] X. Feng, W. Wang, J. Liu, and Y. Liu, " $\beta$-Arrestins: multifunctional signaling adaptors in type 2 diabetes," Molecular Biology Reports, vol. 38, no. 4, pp. 2517-2528, 2011.

[101] F. Mayor, E. Lucas, M. Jurado-Pueyo et al., "G Proteincoupled receptor kinase 2 (GRK2): a novel modulator of insulin resistance," Archives of Physiology and Biochemistry, vol. 117, no. 3, pp. 125-130, 2011.

[102] M. A. R. Vinolo, S. M. Hirabara, and R. Curi, "G-proteincoupled receptors as fat sensors," Current Opinion in Clinical Nutrition and Metabolic Care, vol. 15, no. 2, pp. 112-116, 2012.

[103] Y. Tuo, D. D. Feng, D.-F. Wang, J. Sun, S.-B. Li, and C. Chen, "Long-term in vitro treatment of INS-1 rat pancreatic $\beta$-cells by unsaturated free fatty acids protects cells against glucoand lipotoxicities via activation of GPR40 receptors," Clinical and Experimental Pharmacology and Physiology, vol. 39, no. 5, pp. 423-428, 2012.

[104] Z. L. Chu, R. M. Jones, H. He et al., "A role for $\beta$ cell-expressed G protein-coupled receptor 119 in glycemic control by enhancing glucose-dependent insulin release," Endocrinology, vol. 148, no. 6, pp. 2601-2609, 2007.

[105] S. Edfalk, P. Steneberg, and H. Edlund, "Gpr40 is expressed in enteroendocrine cells and mediates free fatty acid stimulation of incretin secretion," Diabetes, vol. 57, no. 9, pp. 2280-2287, 2008.

[106] A. Hirasawa, K. Tsumaya, T. Awaji et al., "Free fatty acids regulate gut incretin glucagon-like peptide-1 secretion through GPR120," Nature Medicine, vol. 11, no. 1, pp. 90-94, 2005.

[107] K. B. Hansen, M. M. Rosenkilde, F. K. Knop et al., "2-Oleoyl glycerol is a GPR119 agonist and signals GLP-1 release in humans," Journal of Clinical Endocrinology and Metabolism, vol. 96, no. 9, pp. E1409-E1417, 2011.

[108] L. M. Lauffer, R. Iakoubov, and P. L. Brubaker, "GPR119 is essential for oleoylethanolamide-induced glucagon-like peptide-1 secretion from the intestinal enteroendocrine L-cell," Diabetes, vol. 58, no. 5, pp. 1058-1066, 2009.

[109] G. Tolhurst, H. Heffron, Y. S. Lam et al., "Short-chain fatty acids stimulate glucagon-like peptide-1 secretion via the Gprotein-coupled receptor FFAR2," Diabetes, vol. 61, no. 2, pp. 364-371, 2012.

[110] D. Y. Oh, S. Talukdar, E. J. Bae et al., "GPR120 is an omega-3 fatty acid receptor mediating potent anti-inflammatory and insulin-sensitizing effects," Cell, vol. 142, no. 5, pp. 687-698, 2010.

[111] M. A. Glozak, N. Sengupta, X. Zhang, and E. Seto, "Acetylation and deacetylation of non-histone proteins," Gene, vol. 363, no. 1-2, pp. 15-23, 2005.

[112] A. M. Grabiec, P. P. Tak, and K. A. Reedquist, "Function of histone deacetylase inhibitors in inflammation," Critical Reviews in Immunology, vol. 31, no. 3, pp. 233-263, 2011.

[113] D. P. Christensen, M. Dahllöf, M. Lundh et al., "Histone deacetylase (HDAC) inhibition as a novel treatment for diabetes mellitus," Molecular Medicine, vol. 17, no. 5-6, pp. 378-390, 2011.

[114] E. C. Lewis, L. Blaabjerg, J. StØrling et al., "The oral histone deacetylase inhibitor ITF2357 reduces cytokines and protects islet $\beta$ cells in vivo and in vitro," Molecular Medicine, vol. 17, no. 5-6, pp. 369-377, 2011.

[115] Z. Gao, J. Yin, J. Zhang et al., "Butyrate improves insulin sensitivity and increases energy expenditure in mice," Diabetes, vol. 58, no. 7, pp. 1509-1517, 2009.

[116] M. A. R. Vinolo, H. G. Rodrigues, W. T. Festuccia et al., "Tributyrin attenuates obesity-associated inflammation and insulin resistance in high-fat-fed mice," American Journal of Physiology, vol. 303, no. 2, pp. E272-E282, 2012.

[117] H. Li, Z. Gao, J. Zhang et al., "Sodium butyrate stimulates expression of fibroblast growth factor 21 in liver by inhibition of histone deacetylase 3," Diabetes, vol. 61, no. 4, pp. 797-806, 2012.

[118] R. Winkler, V. Benz, M. Clemenz et al., "Histone deacetylase 6 (HDAC6) is an essential modifier of glucocorticoid-induced hepatic gluconeogenesis," Diabetes, vol. 61, no. 2, pp. 513523, 2012.

[119] S. J. Saouaf, B. Li, G. Zhang et al., "Deacetylase inhibition increases regulatory $\mathrm{T}$ cell function and decreases incidence and severity of collagen-induced arthritis," Experimental and Molecular Pathology, vol. 87, no. 2, pp. 99-104, 2009.

[120] R. Tao, E. F. De Zoeten, E. Özkaynak et al., "Deacetylase inhibition promotes the generation and function of regulatory $\mathrm{T}$ cells," Nature Medicine, vol. 13, no. 11, pp. 1299-1307, 2007.

[121] F. Chiarelli and D. Di Marzio, "Peroxisome proliferatoractivated receptor- $\gamma$ agonists and diabetes: current evidence and future perspectives," Vascular Health and Risk Management, vol. 4, no. 2, pp. 297-304, 2008.

[122] N. Guo, C. F. Woeller, S. E. Feldon, and R. P. Phipps, "Peroxisome proliferator-activated receptor $\gamma$ ligands inhibit transforming growth factor- $\beta$-induced, hyaluronan-dependent, $\mathrm{T}$ cell adhesion to orbital fibroblasts," The Journal of Biological Chemistry, vol. 286, no. 21, pp. 18856-18867, 2011. 
[123] M. Hamblin, L. Chang, H. Zhang, K. Yang, J. Zhang, and Y. E. Chen, "Vascular smooth muscle cell peroxisome proliferatoractivated receptor- $\gamma$ mediates pioglitazone-reduced vascular lesion formation," Arteriosclerosis, Thrombosis, and Vascular Biology, vol. 31, no. 2, pp. 352-359, 2011.

[124] A. Foryst-Ludwig, M. Hartge, M. Clemenz et al., "PPARgamma activation attenuates T-lymphocytedependent inflammation of adipose tissue and development of insulin resistance in obese mice," Cardiovascular Diabetology, vol. 9, article 64, 2010.

[125] Y. L. Ye, Z. Zhou, H. J. Zou et al., "Discovery of novel dual functional agent as PPAR $\gamma$ agonist and $11 \beta$-HSD1 inhibitor for the treatment of diabetes," Bioorganic and Medicinal Chemistry, vol. 17, no. 15, pp. 5722-5732, 2009.

[126] Y. F. Zhang, X. Yang, Y. J. Zhang et al., "Peroxisome proliferator-activated receptor-gamma is expressed by rat peritoneal mesothelial cells: its potential role in peritoneal cavity local defense," American Journal of Nephrology, vol. 26, no. 6, pp. 602-611, 2007.

[127] M. Suzawa, I. Takada, J. Yanagisawa et al., "Cytokines suppress adipogenesis and PPAR- $\gamma$ function through the TAK1/ TAB1/NIK cascade," Nature Cell Biology, vol. 5, no. 3, pp. 224-230, 2003.

[128] C. N. Lumeng, S. M. DeYoung, J. L. Bodzin, and A. R. Saltiel, "Increased inflammatory properties of adipose tissue macrophages recruited during diet-induced obesity," Diabetes, vol. 56, no. 1, pp. 16-23, 2007.

[129] H. Tilg and A. R. Moschen, "Inflammatory mechanisms in the regulation of insulin resistance," Molecular Medicine, vol. 14, no. 3-4, pp. 222-231, 2008.

[130] J. I. Odegaard, R. R. Ricardo-Gonzalez, M. H. Goforth et al., "Macrophage-specific PPAR $\gamma$ controls alternative activation and improves insulin resistance," Nature, vol. 447, no. 7148, pp. 1116-1120, 2007.

[131] D. Cipolletta, M. Feuerer, A. Li et al., "PPAR- $\gamma$ is a major driver of the accumulation and phenotype of adipose tissue T reg cells," Nature, vol. 486, no. 7404, pp. 549-553, 2012.

[132] F. Zheng and Y. Guan, "Thiazolidinediones: a novel class of drugs for the prevention of diabetic nephropathy?" Kidney International, vol. 72, no. 11, pp. 1301-1303, 2007.

[133] S. Sakaguchi, T. Yamaguchi, T. Nomura, and M. Ono, "Regulatory T cells and immune tolerance," Cell, vol. 133, no. 5, pp. 775-787, 2008.

[134] M. Feuerer, Y. Shen, D. R. Littman, C. Benoist, and D. Mathis, "How punctual ablation of regulatory $\mathrm{T}$ cells unleashes an autoimmune lesion within the pancreatic islets," Immunity, vol. 31, no. 4, pp. 654-664, 2009.

[135] K. Wu, Y. Bi, K. Sun, and C. Wang, "IL-10-producing type 1 regulatory T cells and allergy," Cellular \& Molecular Immunology, vol. 4, no. 4, pp. 269-275, 2007.

[136] V. De Rosa, C. Procaccini, G. Calì et al., "A key role of leptin in the control of regulatory T cell proliferation," Immunity, vol. 26, no. 2, pp. 241-255, 2007.

[137] A. Aderem and R. J. Ulevitch, "Toll-like receptors in the induction of the innate immune response," Nature, vol. 406, no. 6797 , pp. 782-787, 2000.

[138] D. Shi, J. Das, and G. Das, "Inflammatory bowel disease requires the interplay between innate and adaptive immune signals," Cell Research, vol. 16, no. 1, pp. 70-74, 2006.

[139] M. R. Dasu, S. Devaraj, S. Park, and I. Jialal, "Increased TollLike Receptor (TLR) activation and TLR ligands in recently diagnosed type 2 diabetic subjects," Diabetes Care, vol. 33, no. 4, pp. 861-868, 2010.
[140] M. K. Mohammad, M. Morran, B. Slotterbeck et al., "Dysregulated Toll-like receptor expression and signaling in bone marrow-derived macrophages at the onset of diabetes in the non-obese diabetic mouse," International Immunology, vol. 18, no. 7, pp. 1101-1113, 2006.

[141] H. S. Kim, M. S. Han, K. W. Chung et al., "Toll-like receptor 2 senses beta-cell death and contributes to the initiation of autoimmune diabetes," Immunity, vol. 27, no. 2, pp. 321-333, 2007.

[142] A. Kopp, C. Buechler, M. Bala, M. Neumeier, J. Schölmerich, and A. Schäffler, "Toll-like receptor ligands cause proinflammatory and prodiabetic activation of adipocytes via phosphorylation of extracellular signal-regulated kinase and c-Jun N-terminal kinase but not interferon regulatory factor3," Endocrinology, vol. 151, no. 3, pp. 1097-1108, 2010.

[143] J. E. Davis, N. K. Gabler, J. Walker-Daniels, and M. E. Spurlock, "Tlr-4 deficiency selectively protects against obesity induced by diets high in saturated fat," Obesity, vol. 16, no. 6, pp. 1248-1255, 2008.

[144] C. K. Glass and J. M. Olefsky, "Inflammation and lipid signaling in the etiology of insulin resistance," Cell Metabolism, vol. 15, no. 5, pp. 635-645, 2012.

[145] C. N. Serhan, S. Hong, K. Gronert et al., "Resolvins: a family of bioactive products of omega-3 fatty acid transformation circuits initiated by aspirin treatment that counter proinflammation signals," Journal of Experimental Medicine, vol. 196, no. 8, pp. 1025-1037, 2002.

[146] C. B. Clish, J. A. O’Brien, K. Gronert, G. L. Stahl, N. A. Petasis, and C. N. Serhan, "Local and systemic delivery of a stable aspirin-triggered lipoxin prevents neutrophil recruitment in vivo," Proceedings of the National Academy of Sciences of the United States of America, vol. 96, no. 14, pp. 8247-8252, 1999.

[147] P. K. Mukherjee, V. L. Marcheselli, S. Barreiro, J. Hu, D. Bok, and N. G. Bazan, "Neurotrophins enhance retinal pigment epithelial cell survival through neuroprotectin D1 signaling," Proceedings of the National Academy of Sciences of the United States of America, vol. 104, no. 32, pp. 13152-13157, 2007.

[148] C. N. Serhan, K. Gotlinger, S. Hong et al., "Anti-inflammatory actions of neuroprotectin D1/protectin D1 and its natural stereoisomers: assignments of dihydroxy-containing docosatrienes," Journal of Immunology, vol. 176, no. 3, pp. 1848-1859, 2006.

[149] C. Godson and H. R. Brady, "Lipoxins: novel anti-inflammatory therapeutics?" Current Opinion in Investigational Drugs, vol. 1, no. 3, pp. 380-385, 2000.

[150] A. González-Périz, R. Horrillo, N. Ferré et al., "Obesityinduced insulin resistance and hepatic steatosis are alleviated by $\omega$ - 3 fatty acids: a role for resolvins and protectins," The FASEB Journal, vol. 23, no. 6, pp. 1946-1957, 2009.

[151] P. J. White, M. Arita, R. Taguchi, J. X. Kang, and A. Marette, "Transgenic restoration of long-chain n-3 fatty acids in insulin target tissues improves resolution capacity and alleviates obesity-linked inflammation and insulin resistance in high-fat-fed mice," Diabetes, vol. 59, no. 12, pp. 3066-3073, 2010.

[152] R. Horrillo, A. González-Périz, M. Martínez-Clemente et al., "5-Lipoxygenase activating protein signals adipose tissue inflammation and lipid dysfunction in experimental obesity," Journal of Immunology, vol. 184, no. 7, pp. 3978-3987, 2010.

[153] E. Titos, B. Rius, A. González-Périz et al., "Resolvin D1 and its precursor docosahexaenoic acid promote resolution of 
adipose tissue inflammation by eliciting macrophage polarization toward an M2-like phenotype," Journal of Immunology, vol. 187, no. 10, pp. 5408-5418, 2011.

[154] J. Hellmann, Y. Tang, M. Kosuri, A. Bhatnagar, and M. Spite, "Resolvin D1 decreases adipose tissue macrophage accumulation and improves insulin sensitivity in obese-diabetic mice," The FASEB Journal, vol. 25, no. 7, pp. 2399-2407, 2011.

[155] V. Ambros, "The functions of animal microRNAs," Nature, vol. 431, no. 7006, pp. 350-355, 2004.

[156] D. P. Bartel, "MicroRNAs: target recognition and regulatory functions," Cell, vol. 136, no. 2, pp. 215-233, 2009.

[157] A. M. Yu, "Role of microRNAs in the regulation of drug metabolism and disposition," Expert Opinion on Drug Metabolism and Toxicology, vol. 5, no. 12, pp. 1513-1528, 2009.

[158] I. Bentwich, A. Avniel, Y. Karov et al., "Identification of hundreds of conserved and nonconserved human microRNAs," Nature Genetics, vol. 37, no. 7, pp. 766-770, 2005.

[159] R. C. Friedman, K. K. H. Farh, C. B. Burge, and D. P. Bartel, "Most mammalian mRNAs are conserved targets of microRNAs," Genome Research, vol. 19, no. 1, pp. 92-105, 2009.

[160] E. M. Small and E. N. Olson, "Pervasive roles of microRNAs in cardiovascular biology," Nature, vol. 469, no. 7330, pp. 336-342, 2011.

[161] K. J. Moore, K. J. Rayner, Y. Suárez, and C. FernándezHernando, "The role of MicroRNAs in cholesterol efflux and hepatic lipid metabolism," Annual Review of Nutrition, vol. 31, pp. 49-63, 2011.

[162] J. Lu, G. Getz, E. A. Miska et al., "MicroRNA expression profiles classify human cancers," Nature, vol. 435, no. 7043, pp. 834-838, 2005.

[163] C. Underbayev, S. Kasar, Y. Yuan, and E. Raveche, "MicroRNAs and induced pluripotent stem cells for human disease mouse modeling," Journal of Biomedicine and Biotechnology, vol. 2012, Article ID 758169, 7 pages, 2012.

[164] J. Ju, "MiRNAs as biomarkers in colorectal cancer diagnosis and prognosis," Bioanalysis, vol. 2, no. 5, pp. 901-906, 2010.

[165] H. Schwarzenbach, D. S. B. Hoon, and K. Pantel, "Cellfree nucleic acids as biomarkers in cancer patients," Nature Reviews Cancer, vol. 11, no. 6, pp. 426-437, 2011.

[166] H. Xie, B. Lim, and H. F. Lodish, "MicroRNAs induced during adipogenesis that accelerate fat cell development are downregulated in obesity," Diabetes, vol. 58, no. 5, pp. 1050 1057, 2009.

[167] M. Hulsmans, D. De Keyzer, and P. Holvoet, "MicroRNAs regulating oxidative stress and inflammation in relation to obesity and atherosclerosis," The FASEB Journal, vol. 25, no. 8, pp. 2515-2527, 2011.

[168] R. J. A. Frost and E. N. Olson, "Control of glucose homeostasis and insulin sensitivity by the Let-7 family of microRNAs," Proceedings of the National Academy of Sciences of the United States of America, vol. 108, no. 52, pp. 21075-21080, 2011.

[169] R. Harmancey, C. R. Wilson, and H. Taegtmeyer, "Adaptation and maladaptation of the heart in obesity," Hypertension, vol. 52, no. 2, pp. 181-187, 2008.

[170] C. E. Grueter, E. Van Rooij, B. A. Johnson et al., "A cardiac MicroRNA governs systemic energy homeostasis by regulation of MED13," Cell, vol. 149, no. 3, pp. 671-683, 2012.

[171] S. Han, C. P. Liang, T. DeVries-Seimon et al., "Macrophage insulin receptor deficiency increases ER stress-induced apoptosis and necrotic core formation in advanced atherosclerotic lesions," Cell Metabolism, vol. 3, no. 4, pp. 257-266, 2006.
[172] I. Tabas, A. Tall, and D. Accili, "The impact of macrophage insulin resistance on advanced atherosclerotic plaque progression," Circulation Research, vol. 106, no. 1, pp. 58-67, 2010.

[173] M. Hulsmans, E. van Dooren, C. Mathieu, and P. Holvoet, "Decrease of miR-146b-5p in monocytes during obesity is associated with loss of the anti-inflammatory but not insulin signaling action of adiponectin," PLoS ONE, vol. 7, no. 2, Article ID e32794, 2012.

[174] N. H. Foley and L. A. O'Neill, “miR-107: a Toll-like receptor-regulated miRNA dysregulated in obesity and type II diabetes," Journal of Leukocyte Biology, vol. 92, no. 3, pp. 521-527, 2012.

[175] E. J. Hennessy, F. J. Sheedy, D. Santamaria, M. Barbacid, and L. A. J. O’Neill, “Toll-like receptor-4 (TLR4) down-regulates microRNA-107, increasing macrophage adhesion via cyclindependent kinase 6," The Journal of Biological Chemistry, vol. 286, no. 29, pp. 25531-25539, 2011.

[176] X. Tang, L. Muniappan, G. Tang, and S. Özcan, "Identification of glucose-regulated miRNAs from pancreatic $\beta$ cells reveals a role for miR-30d in insulin transcription," $R N A$, vol. 15, no. 2, pp. 287-293, 2009.

[177] B. M. Herrera, H. E. Lockstone, J. M. Taylor et al., "Global microRNA expression profiles in insulin target tissues in a spontaneous rat model of type 2 diabetes," Diabetologia, vol. 53, no. 6, pp. 1099-1109, 2010.

[178] M. Trajkovski, J. Hausser, J. Soutschek et al., "MicroRNAs 103 and 107 regulate insulin sensitivity," Nature, vol. 474, no. 7353, pp. 649-653, 2011. 

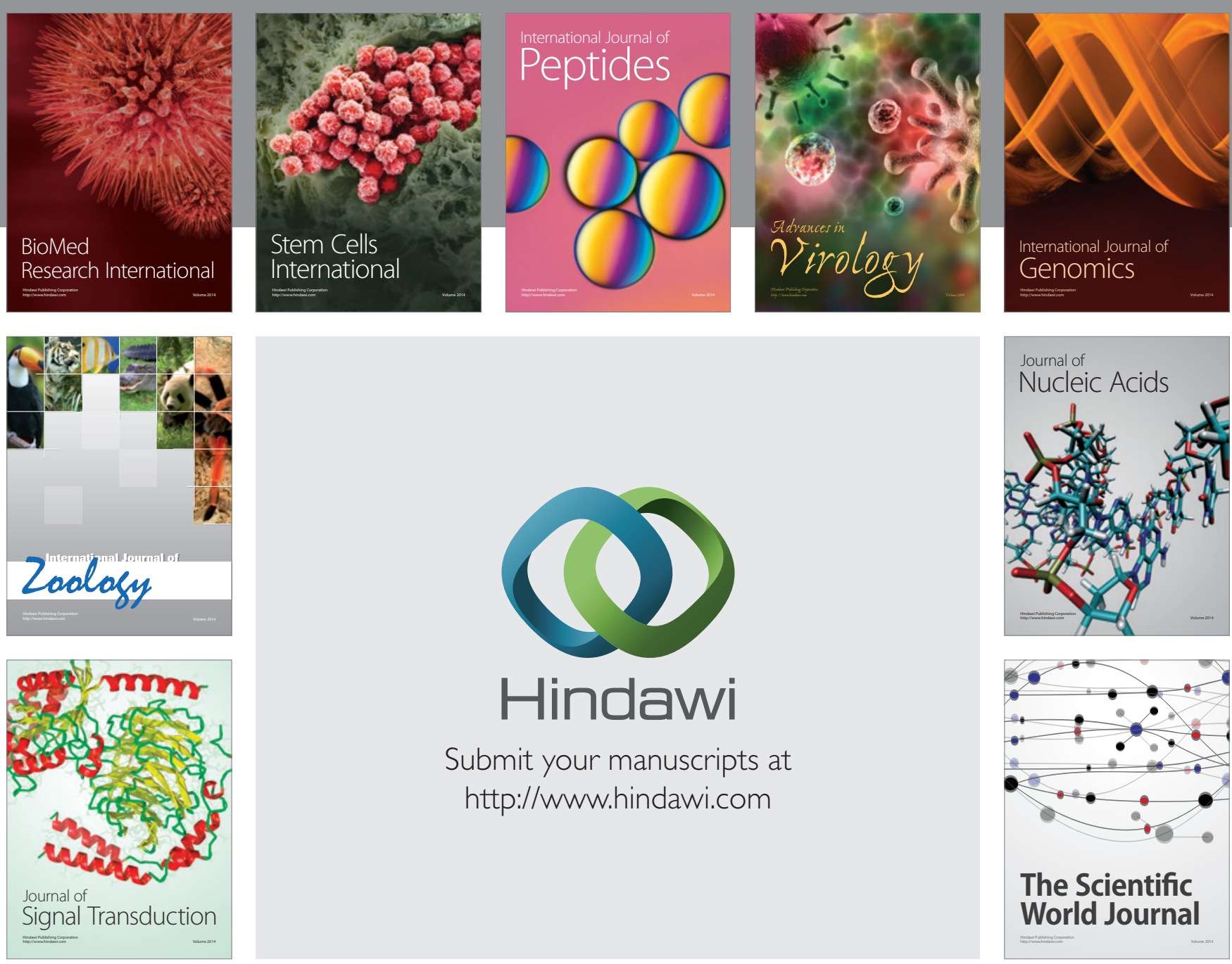

Submit your manuscripts at

http://www.hindawi.com
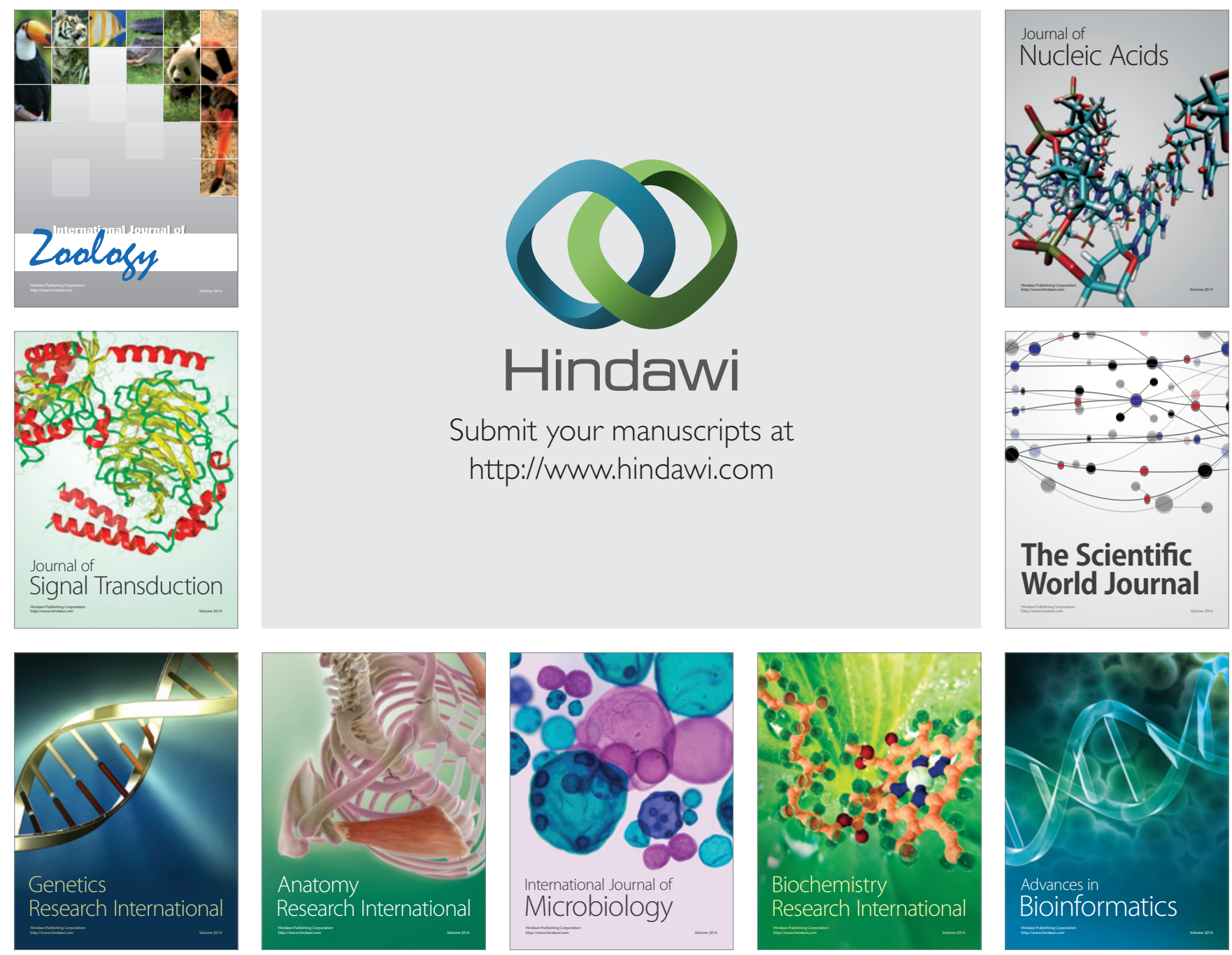

The Scientific World Journal
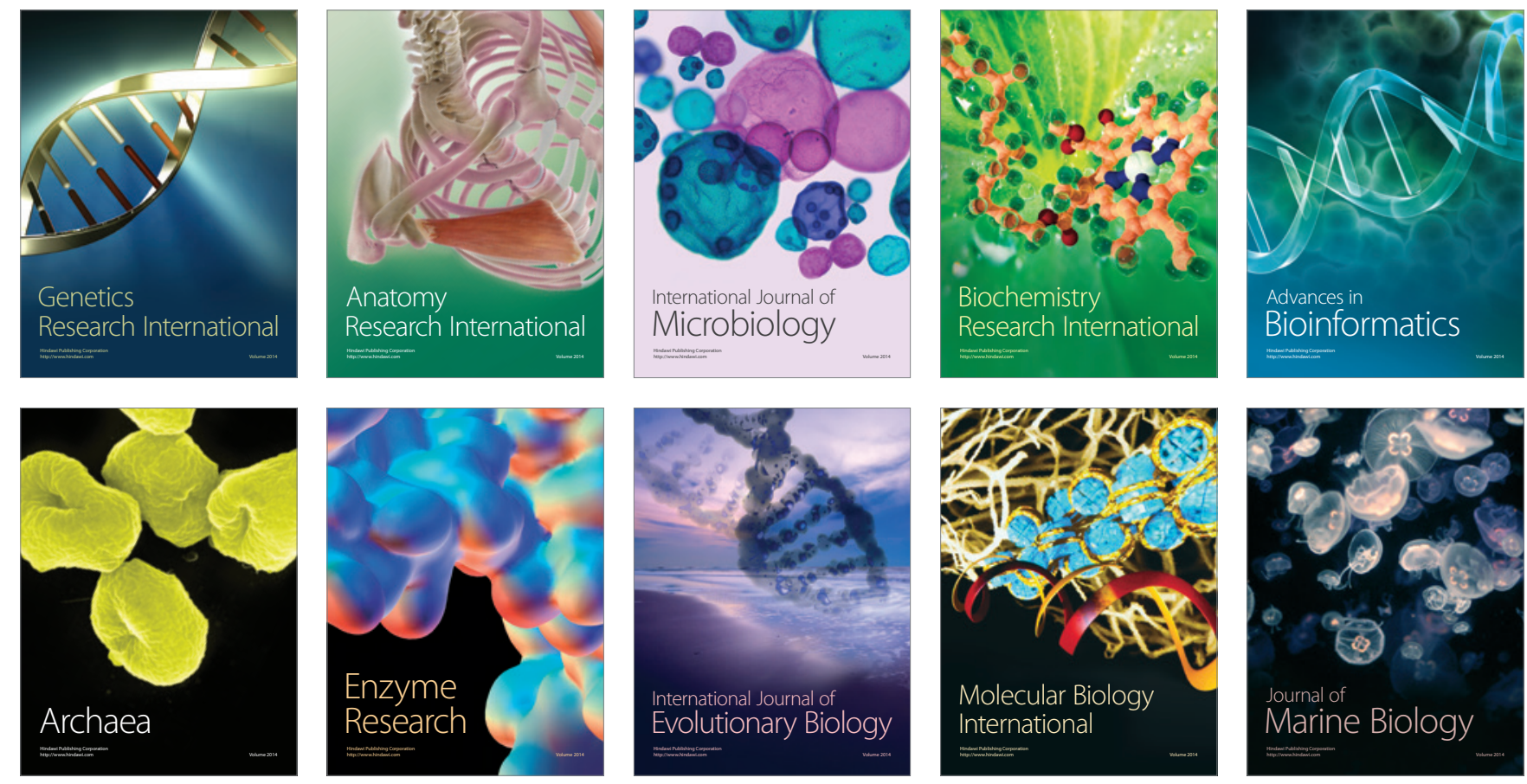